\title{
Benthic archaea as potential sources of tetraether membrane lipids in sediments across an oxygen minimum zone
}

\author{
Marc A. Besseling ${ }^{1}$, Ellen C. Hopmans ${ }^{1}$, R. Christine Boschman ${ }^{1}$, Jaap S. Sinninghe Damsté ${ }^{1,2}$, and Laura Villanueva ${ }^{1}$ \\ ${ }^{1}$ NIOZ Royal Netherlands Institute for Sea Research, Department of Marine Microbiology and Biogeochemistry, \\ and Utrecht University. P.O. Box 59, 1790 AB Den Burg, the Netherlands \\ ${ }^{2}$ Utrecht University, Faculty of Geosciences, Department of Earth sciences, P.O. Box 80.021, \\ 3508 TA Utrecht, the Netherlands
}

Correspondence: Marc A. Besseling (marc.besseling@nioz.nl)

Received: 6 July 2017 - Discussion started: 19 July 2017

Revised: 25 May 2018 - Accepted: 13 June 2018 - Published: 4 July 2018

\begin{abstract}
Benthic archaea comprise a significant part of the total prokaryotic biomass in marine sediments. Recent genomic surveys suggest they are largely involved in anaerobic processing of organic matter, but the distribution and abundance of these archaeal groups are still largely unknown. Archaeal membrane lipids composed of isoprenoid diethers or tetraethers (glycerol dibiphytanyl glycerol tetraether, GDGT) are often used as archaeal biomarkers. Here, we compare the archaeal diversity and intact polar lipid (IPL) composition in both surface $(0-0.5 \mathrm{~cm})$ and subsurface $(10-12 \mathrm{~cm})$ sediments recovered within, just below, and well below the oxygen minimum zone (OMZ) of the Arabian Sea. Archaeal 16S rRNA gene amplicon sequencing revealed a predominance of Thaumarchaeota (Marine Group I, MG-I) in oxygenated sediments. Quantification of archaeal 16S rRNA and ammonia monoxygenase (amoA) of Thaumarchaeota genes and their transcripts indicated the presence of an active in situ benthic population, which coincided with a high relative abundance of hexose phosphohexose crenarchaeol, a specific biomarker for living Thaumarchaeota. On the other hand, anoxic surface sediments within the OMZ and all subsurface sediments were dominated by archaea belonging to the Miscellaneous Crenarchaeota Group (MCG), the Thermoplasmatales and archaea of the DPANN (superphylum grouping Micrarchaeota, Diapherotrites, Aenigmarchaeota, Nanohaloarchaeota, Parvarchaeota, Nanoarchaeota, Pacearchaeota and Woesearchaeota). Members of the MCG were diverse, with a dominance of subgroup MCG-12 in anoxic surface sediments. This coincided with a high relative abundance of IPL GDGT-0 with an unknown polar head group. Subsur-
\end{abstract}

face anoxic sediments were characterized by higher relative abundance of GDGT-0, -2 and -3 with dihexose IPL types, GDGT-0 with a cyclopentanetetraol molecule and hexose, as well as the presence of specific MCG subgroups, suggesting that these groups could be the biological sources of these archaeal lipids.

\section{Introduction}

Archaea are ubiquitous microorganisms in the marine system (DeLong et al., 1994; Delong and Pace, 2001; Schleper et al., 2005). They occur in diverse environments, e.g., hydrothermal vents (Stetter et al., 1990), the marine water column (Karner et al., 2001; Massana et al., 2004), in the underlying sediments (Lloyd et al., 2013; Teske and Sørensen, 2008), and well below the seafloor (Biddle et al., 2006; Lipp et al., 2008), where they are considered key players in diverse biogeochemical processes (Offre et al., 2013, and references cited therein). Specifically, marine sediments have been shown to contain a highly diverse archaeal community (Lloyd et al., 2013; Spang et al., 2017; Teske, 2013; Teske and Sørensen, 2008). The ammonia-oxidizing Thaumarchaeota of marine group I.1a (further referred to as MGI) are probably the most widely studied archaeal group in marine sediments. However, in comparison with studies of marine pelagic Thaumarchaeota, the diversity and distribution of benthic Thaumarchaeota are still not well established (e.g., Durbin and Teske, 2010; Jorgenson et al., 2012; Learman et al., 2016). Genomic studies have revealed the existence 
of uncultured archaeal groups other than Thaumarchaeota in marine, predominantly anoxic, sediments such as the Miscellaneous Crenarchaeota Group (MCG; Meng et al., 2014), archaea of the DPANN superphylum (composed of Micrarchaeota, Diapherotrites, Aenigmarchaeota, Nanohaloarchaeota, Parvarchaeota, Nanoarchaeota, Pacearchaeota and Woesearchaeota; Castelle et al., 2015; Rinke et al., 2013) and Marine Benthic Group (MBG) B (Teske and Sørensen, 2008), and Marine Benthic Group D (Lloyd et al., 2013). In the case of the archaea belonging to the groups of the MCG and MBG-D, metagenomic studies suggest that they are able to degrade extracellular proteins and aromatic compounds (Lloyd et al., 2013; Meng et al., 2014).

Archaeal diversity is currently determined through nucleic acid-based methods, but the characterization of other cellular biomarkers such as membrane lipids has proven to be also effective in tracking the presence of archaeal groups in different ecosystems (e.g., Coolen et al., 2004a; Ingalls et al., 2012; Meador et al., 2015; Pitcher et al., 2011; Sturt et al., 2004). One of the advantages of using lipid-based methods to determine the presence of archaeal groups is that lipids can be preserved in the sedimentary record. Therefore, they can also be used as biomarkers of the presence and metabolic potential of these microorganisms in past environments. In contrast, other biomolecules like DNA have a more rapid turnover and they cannot be used for this purpose. In recent years, intact polar lipids (IPLs) have increasingly been applied for tracing "living" bacteria and archaea in the environment (Lipp et al., 2008; Lipp and Hinrichs, 2009; Rossel et al., 2008). IPLs with polar head groups are present in living cells, but upon cell lysis the polar head groups are lost, releasing core lipids (CLs) that may be preserved in the fossil record. Since IPLs degrade relatively quickly after cell death (Harvey et al., 1986), it is possible to associate the presence of IPLs in the environment with the occurrence of their living producers (Lipp and Hinrichs, 2009; Schubotz et al., 2009).

Archaeal membrane lipids are typically a variation of two main structures, $s n$-2,3-diphytanylglycerol diether (archaeol) with phytanyl $\left(\mathrm{C}_{20}\right)$ chains in a bilayer structure, and $s n$ 2,3-dibiphytanyl diglycerol tetraether (glycerol dibiphytanyl glycerol tetraether, GDGT), in which the two glycerol moieties are connected by two $\mathrm{C}_{40}$ isoprenoid chains, allowing the formation of a monolayer membrane (Koga and Morii, 2007). GDGTs containing zero to four cyclopentane moieties (Fig. S1 in the Supplement) are usually not exclusive to a specific archaeal group (Schouten et al., 2013), with the exception of the GDGT crenarchaeol, containing four cyclopentane moieties and one cyclohexane moiety, which is deemed to be exclusive to the Thaumarchaeota phylum (De La Torre et al., 2008; Sinninghe Damsté et al., 2002, 2012). Recently, Lincoln et al. (2014a) proposed Marine Group II as potential producers of crenarchaeol. However, this is still debated (Lincoln et al., 2014b; Schouten et al., 2014). The newly described archaeal groups detected by genetic methods are still uncultured; therefore, their membrane lipid composition remains unknown.

In this study, we determined the archaeal diversity in a marine benthic system along a strong gradient in bottom water oxygen concentrations and compared it with the diversity of archaeal lipids. We aimed to characterize changes in the archaeal benthic community under different physicochemical conditions, as well as to provide clues to the potential archaeal lipid biomarkers produced by uncultured benthic archaea. We analyzed sediments (surface $0-0.5 \mathrm{~cm}$, and subsurface 10-12 cm) of the Murray Ridge in the Arabian Sea, which is impinged by one of the strongest present-day oxygen minimum zones (OMZs). Previous studies observed changes in the diversity of archaeal lipids in the same environmental setting in sediments under different oxygen and nutrient concentrations (Lengger et al., 2012, 2014). In our study, we expand the repertoire of archaeal lipid diversity previously detected by Lengger et al. $(2012,2014)$ by analyzing these sediments with high-resolution accurate mass/mass spectrometry (UHPLC-HRAM MS). In addition, we determined the archaeal diversity by means of 16S rRNA gene amplicon sequencing, as well as the abundance and potential activity of specific archaeal groups by quantitative PCR (QPCR) of 16S rRNA and the metabolic gene coding for the ammonia monoxygenase (amoA gene) of Thaumarchaeota.

\section{Material and methods}

\subsection{Sampling}

Sediments were collected in the northern Arabian Sea during the PASOM cruise in January 2009 with R/V Pelagia. Sediment cores obtained with a multicorer were taken on the Murray Ridge at four depths, $885 \mathrm{~m}$ below sea level (m b.s.l.) (within the OMZ), at $1306 \mathrm{~m}$ b.s.l. (just below the OMZ), and at 2470 and $3003 \mathrm{~m}$ b.s.l. (both well below the OMZ) as previously described by Lengger et al. (2012). Upon retrieval the cores were sliced in $0.5 \mathrm{~cm}$ resolution for the first $2 \mathrm{~cm}$ and at $2 \mathrm{~cm}$ resolution beyond $10 \mathrm{~cm}$ below the surface, and stored at $-80^{\circ} \mathrm{C}$ until further analysis. For an overview of the surface sediment physicochemical conditions, see Table 1.

\subsection{Lipid extraction and analysis}

Total lipids were extracted from surface (upper $0-0.5 \mathrm{~cm}$ ) and subsurface $(10-12 \mathrm{~cm})$ sediments after freeze-drying using a modified Bligh and Dyer method (Bligh and Dyer, 1959) as previously described by Lengger et al. (2014). C 16 -PAF (1-O-hexadecyl-2-acetoyl-sn-glycero-3phosphocholine) was added to the extracts as an internal standard and the extracts were dried under a stream of nitrogen. The extracts with the added standard were then dissolved by adding solvent (hexane : isopropanol: $\mathrm{H}_{2} \mathrm{O} 718: 271: 10$ $[v / v / v / v])$ and filtered through a $0.45 \mu \mathrm{m}, 4 \mathrm{~mm}$ diameter 
Table 1. Bottom water temperature and bottom water oxygen (BWO) concentration, oxygen penetration depth (OPD) in the sediment, and TOC content and pore water composition of the surface $(0-0.5 \mathrm{~cm})$ sediment $^{\mathrm{a}}$.

\begin{tabular}{lrrrrrrrr}
\hline $\begin{array}{l}\text { Station } \\
(\mathrm{m} \text { b.s.1. })\end{array}$ & $\begin{array}{r}T \\
\left({ }^{\circ} \mathrm{C}\right)\end{array}$ & $\begin{array}{r}\mathrm{BWO} \\
(\mu \mathrm{mol} \mathrm{L}-1)\end{array}$ & $\begin{array}{r}\mathrm{OPD} \\
(\mathrm{mm})\end{array}$ & $\begin{array}{r}\mathrm{TOC} \\
(\mathrm{wt} \%)\end{array}$ & $\begin{array}{r}\mathrm{NH}_{4}^{+} \\
(\mu \mathrm{M})\end{array}$ & $\begin{array}{r}\mathrm{NO}_{2}^{-} \\
(\mu \mathrm{M})\end{array}$ & $\begin{array}{r}\mathrm{NO}_{3}^{-} \\
(\mu \mathrm{M})\end{array}$ & $\begin{array}{r}\mathrm{HPO}_{4}^{2-} \\
(\mu \mathrm{M})\end{array}$ \\
\hline 885 & 10 & 2.0 & 0.1 & $5.6( \pm 0.2)$ & 2 & 1.2 & 1.3 & 9.2 \\
1306 & 6.7 & 14.3 & 2.9 & $2.9( \pm 0.1)$ & $2.6^{*}$ & $0.1^{*}$ & $36.2^{*}$ & 5.6 \\
2470 & 2.1 & 63.8 & 9.8 & $0.8( \pm 0.1)$ & $-{ }^{\mathrm{b}}$ & - & - & - \\
3003 & 1.4 & 82.9 & 19 & $0.7( \pm 0.1)$ & 55.6 & 8.3 & 46.2 & 3.8 \\
\hline
\end{tabular}

${ }^{a}$ Data from Kraal et al. (2012) and Lengger et al. (2014). ${ }^{\text {b }}$ No data available.

True Regenerated Cellulose syringe filter (Grace Davison, Columbia, MD, USA).

IPLs were analyzed according to Sturt et al. (2004) with some modifications. An Ultimate 3000 RS UHPLC, equipped with thermostated auto-injector and column oven, coupled to a Q Exactive Orbitrap MS with Ion Max source with heated electrospray ionization (HESI) probe (Thermo Fisher Scientific, Waltham, MA), was used. Separation was achieved on a YMC-Triart Diol-HILIC column $(250 \times 2.0 \mathrm{~mm}, 1.9 \mu \mathrm{m}$ particles, pore size $12 \mathrm{~nm}$; YMC Co., Ltd, Kyoto, Japan) maintained at $30^{\circ} \mathrm{C}$. The following elution program was used with a flow rate of $0.2 \mathrm{~mL} \mathrm{~min}^{-1}$ : $100 \% \mathrm{~A}$ for $5 \mathrm{~min}$, followed by a linear gradient to $66 \% \mathrm{~A}$; $34 \% \mathrm{~B}$ in $20 \mathrm{~min}$, maintained for $15 \mathrm{~min}$, followed by a linear gradient to $40 \% \mathrm{~A} ; 60 \% \mathrm{~B}$ in $15 \mathrm{~min}$, followed by a linear gradient to $30 \% \mathrm{~A} ; 70 \% \mathrm{~B}$ in $10 \mathrm{~min}$, where $\mathrm{A}=$ hexane $/ 2$ propanol/formic acid/14.8 M NH 3 aq $(79: 20: 0.12: 0.04$ $[v / v / v / v])$ and $\mathrm{B}=2$-propanol/water/formic acid/14.8 $\mathrm{M}$ $\mathrm{NH}_{3 \mathrm{aq}}(88: 10: 0.12: 0.04[v / v / v / v])$. Total run time was $70 \mathrm{~min}$ with a re-equilibration period of $20 \mathrm{~min}$ in between runs. HESI settings were as follows: sheath gas $\left(\mathrm{N}_{2}\right)$ pressure 35 (arbitrary units), auxiliary gas $\left(\mathrm{N}_{2}\right)$ pressure 10 (arbitrary units), auxiliary gas $\left(\mathrm{N}_{2}\right) T 50^{\circ} \mathrm{C}$, sweep gas $\left(\mathrm{N}_{2}\right)$ pressure 10 (arbitrary units), spray voltage $4.0 \mathrm{kV}$ (positive ion ESI), capillary temperature $275^{\circ} \mathrm{C}$, S-Lens $70 \mathrm{~V}$. IPLs were analyzed with a mass range of $m / z 375$ to 2000 (resolving power 70000 at $m / z$ 200), followed by data-dependent $\mathrm{MS}^{2}$ (resolving power $17500 \mathrm{ppm}$ at $\mathrm{m} / z 200$ ), in which the 10 most abundant masses in the mass spectrum (with the exclusion of isotope peaks) were fragmented (stepped normalized collision energy 15, 22.5, 30; isolation window $1.0 \mathrm{~m} / \mathrm{z}$ ). A dynamic exclusion window of $6 \mathrm{~s}$ was used as well as an inclusion list with a mass tolerance of $3 \mathrm{ppm}$ to target specific compounds (Table S1 in the Supplement). The Q Exactive Orbitrap MS was calibrated within a mass accuracy range of 1 using the Thermo Scientific Pierce LTQ Velos ESI Positive Ion Calibration Solution (containing a mixture of caffeine, MRFA, Ultramark 1621, and $N$-butylamine in an acetonitrile-methanol-acetic acid solution).

Peak areas for each individual IPL were determined by integrating the combined mass chromatogram (within $3 \mathrm{ppm}$ ) of the monoisotopic and first isotope peak of all relevant adducts formed (protonated, ammoniated and/or sodiated adducts may be formed in different proportions depending on the type of IPL). PAF was used as an internal standard to continuously monitor MS performance and to assess matrix effects. Reported peak areas have been corrected for these effects. Absolute quantification of IPL GDGTs was not possible due to a lack of standards. Peak areas were not corrected for any possible differences in response factors between the various classes of IPL-crenarchaeol. IPLs with the same head group but with the regioisomer of crenarchaeol instead of crenarchaeol as the CL co-elute on the chromatographic system used here and any peak area reported for a crenarchaeol IPL thus represent the sum of both isomers.

To rule out any degradation of the GDGT-IPLs during storage of the sediments at $-20^{\circ} \mathrm{C}$, the anoxic surface sediment sample at $885 \mathrm{~m}$ b.s.l. was also analyzed according to the method previously used by Lengger et al. (2012). The IPL fraction was separated from the CLs with the use of a silica column and elution with $\mathrm{MeOH}$ (Lengger et al., 2012). This IPL fraction was hydrolyzed for $3 \mathrm{~h}$ and analyzed by HPLC-APCI/MS (according to Hopmans et al., 2016) and the IPL-derived CL-GDGT distribution was compared with previously published data.

\subsection{Nucleic acids extraction, cDNA synthesis and quantitative PCR (QPCR) analyses}

Sediment was centrifuged and the excess of water was removed by pipetting before proceeding with the extraction of nucleic acids from the sediment. DNA/RNA of surface $(0-0.5 \mathrm{~cm})$ and subsurface $(10-12 \mathrm{~cm})$ sediments was extracted with the RNA PowerSoil ${ }^{\circledR}$ Total Isolation Kit plus the DNA elution accessory (Mo Bio Laboratories, Carlsbad, CA). Concentrations of DNA and RNA were quantified by Nanodrop (Thermo Scientific, Waltham, MA) and Fluorometric with a Quant-iT ${ }^{\mathrm{TM}}$ PicoGreen ${ }^{\circledR}$ dsDNA Assay Kit (Life technologies, Netherlands). RNA extracts were treated with DNAse and reverse-transcribed to cDNA as described by Pitcher et al. (2011). Quantification of archaeal 16S rRNA gene copies and amoA gene copies was estimated by QPCR by using the following primers: Parch519F and ARC915R (archaeal 16S rRNA gene), and CrenAmoAQ-F and Cren- 
AmoAModR (amoA gene), as previously described (Pitcher et al., 2011). For details on the QPCR conditions, efficiency and $R^{2}$ of the QPCR assays, see Table $\mathrm{S} 2$.

\subsection{S rRNA gene amplicon sequencing, analysis, and phylogeny}

PCR reactions were performed with the universal, bacteria and archaea primers S-D-Arch-0159-a-S-15 and S-DBact-785-a-A-21 (Klindworth et al., 2013) as previously described in Moore et al. (2015). The archaeal 16S rRNA gene amplicon sequences were analyzed by QIIME v1.9 (Caporaso et al., 2010). Raw sequences were demultiplexed and then quality-filtered with a minimum quality score of 25 and length between 250 and 350, and allowing a maximum of two errors in the barcode sequence. Taxonomy was assigned based on blast and the SILVA database version 123 (Altschul et al., 1990; Quast et al., 2013). Representative operational taxonomic units (OTUs, clusters of reads with $97 \%$ similarity) of archaeal groups were extracted through filter_taxa_from_otu_table.py and filter_fasta.py with QIIME (Caporaso et al., 2010). The phylogenetic affiliation of the partial archaeal 16S rRNA gene sequences was compared to release 123 of the SILVA NR SSU Ref database (http: //www.arb-silva.de/, last access: 7 March 2016; Quast et al., 2013) using the ARB software package (Ludwig et al., 2004). Sequences were added to the reference tree supplied by the SILVA database using the ARB Parsimony tool. MCG intragroup phylogeny for representative sequences of OTUs affiliated with the MCG lineage was carried out in ARB (Ludwig et al., 2004). Sequences were added by parsimony to a previously built phylogenetic tree composed of reference sequences of the 17 MCG subgroups known so far (Kubo et al., 2012). Affiliation of any $16 \mathrm{~S}$ rRNA gene sequences with a given subgroup was done assuming a similarity cutoff of $\geq 85 \%$.

\subsection{Cloning, sequencing and phylogeny of the archaeal amo A gene}

Amplification of the archaeal amoA gene was performed as described by Yakimov et al. (2011). The PCR reaction mixture was the following (final concentration): Qsolution $1 \times$ (PCR additive, Qiagen); PCR buffer $1 \times$; BSA $\left(200 \mu \mathrm{g} \mathrm{mL}^{-1}\right)$; dNTPs $(20 \mu \mathrm{M})$; primers $\left(0.2 \mathrm{pmol} \mathrm{L}^{-1}\right)$; $\mathrm{MgCl}_{2}(1.5 \mathrm{mM}) ; 1.25 \mathrm{U}$ Taq polymerase (Qiagen, Valencia, CA, USA). PCR conditions for these amplifications were the following: $95^{\circ} \mathrm{C}, 5 \mathrm{~min} ; 35 \times\left[95^{\circ} \mathrm{C}, 1 \mathrm{~min} ; 55^{\circ} \mathrm{C}, 1 \mathrm{~min}\right.$; $72^{\circ} \mathrm{C}, 1 \mathrm{~min}$ ]; final extension $72^{\circ} \mathrm{C}, 5 \mathrm{~min}$. PCR products were gel purified (QIAquick gel purification kit, Qiagen), cloned in the TOPO-TA cloning ${ }^{\circledR}$ kit from Invitrogen (Carlsbad, CA, USA) and transformed in E. coli TOP10 cells following the manufacturer's recommendations. Recombinant clone plasmid DNAs were purified by the Qiagen Miniprep kit and screening by sequencing $(n \geq 30)$ using an M13R primer by Macrogen Europe Inc. (Amsterdam, the Netherlands). Obtained archaeal amoA protein sequences were aligned with already annotated amoA sequences by using the MUSCLE application (Edgar, 2004). Phylogenetic trees were constructed with the neighbor-joining method (Saitou and Nei, 1987) and evolutionary distances computed using the Poisson correction method with a bootstrap test of 1000 replicates.

\section{Results}

In this study, we analyzed both IPLs and DNA/RNA extracts from sediments previously collected along the Arabian Sea Murray Ridge within the OMZ ( $885 \mathrm{~m}$ b.s.l.), just below the lower interface (1306 m b.s.l.), and well below the OMZ (2470 and $3003 \mathrm{~m}$ b.s.l.). The surface sediment $(0-0.5 \mathrm{~cm})$ at $885 \mathrm{~m}$ b.s.l. was fully anoxic; however, the surface sediments below the OMZ were partly oxygenated (1306 m b.s.l.), and fully oxygenated at 2470 and $3003 \mathrm{mb}$.s.l. (Table 1). The subsurface sediments $(10-12 \mathrm{~cm})$ were fully anoxic at all stations (Table 1). For more details on the physicochemical conditions in these sediments, see Table 1.

\subsection{Archaeal IPL-GDGTs in the surface and subsurface sediments}

A range of IPL-GDGTs (GDGT-0 to -4 and crenarchaeol) with IPL types monohexose (MH), dihexose (DH) and hexose-phosphohexose (HPH) was detected in surface and subsurface sediments across the Arabian Sea OMZ (Table 2). For the DH GDGT-0 two structural isomers (type-I with two hexose moieties at both ends of the CL, and type-II with one dihexose moiety; Table 2) were detected and identified based on their mass spectral characteristics (Fig. S2). These isomers were previously also reported in thaumarchaeotal cultures (Elling et al., 2014, 2017). In addition, GDGT-0 with both an ether-bound cyclopentanetetraol moiety and a hexose moiety as head groups was identified (Fig. S2) in some sediments (Table 2). This IPL was previously reported as a glycerol dibiphytanyl nonitol tetraether (GDNT; de Rosa et al., 1988), but was later shown to contain a 2-hydroxymethyl-1(2,3-dihydroxypropoxy)-2,3,4,5-cyclopentanetetraol moiety by Sugai et al. (1995) on the basis of NMR spectroscopy characterization.

In the surface sediment at $885 \mathrm{~m}$ b.s.1., crenarchaeol IPLs were dominant ( $44.7 \%$ of all detected IPL-GDGTs), occurring predominantly with DH as IPL type (with a hexose head group on both ends; $43.1 \%$; Table 2). IPL-GDGT-2 was the second most abundant (29.6\%), also mainly consisting of the DH IPL type (29.5\%; Table 2). IPL-GDGT-0, -1, -3 and -4 occurred with relative abundances of $0.3,1.7,17.8$ and $6.1 \%$, respectively (Table 2). Overall, the majority (98.1\%; Table 3 ) of IPL-GDGTs are in surface sediment at $885 \mathrm{~m}$ b.s.l. with 
Table 2. Total IPL abundance and heat map ${ }^{\mathrm{a}}$ of the relative abundance $(\%)$ of the detected IPLs and sum (not color coded) per IPL-GDGT in the sediments studied.

\begin{tabular}{|c|c|c|c|c|c|c|c|c|c|c|c|c|c|c|c|}
\hline \multirow[b]{3}{*}{ Sediment } & \multirow{3}{*}{$\begin{array}{c}\text { Depth } \\
\text { (m b.s.l.) }\end{array}$} & \multicolumn{6}{|c|}{ GDGT-0 } & \multicolumn{4}{|c|}{ GDGT-1 } & \multicolumn{4}{|c|}{ GDGT-2 } \\
\hline & & \multirow[t]{2}{*}{ MH } & \multicolumn{2}{|c|}{ DH } & \multirow[t]{2}{*}{$\mathrm{HCP}^{\circ}$} & \multirow[t]{2}{*}{ HPH } & \multirow[t]{2}{*}{ Sum } & \multirow[t]{2}{*}{$\mathrm{MH}$} & \multirow{2}{*}{$\begin{array}{l}\text { DH } \\
\text { I }^{\mathrm{b}}\end{array}$} & \multirow[t]{2}{*}{$\mathrm{HPH}$} & \multirow[t]{2}{*}{ Sum } & \multirow[t]{2}{*}{ MH } & \multirow{2}{*}{$\begin{array}{l}\mathrm{DH} \\
\mathrm{I}^{\mathrm{b}}\end{array}$} & \multirow{2}{*}{ HPH } & \multirow[t]{2}{*}{ Sum } \\
\hline & & & $I^{\mathrm{b}}$ & II $^{\mathrm{b}}$ & & & & & & & & & & & \\
\hline \multirow{4}{*}{$\begin{array}{l}\text { Surface } \\
(0-0.5 \mathrm{~cm})\end{array}$} & 885 & 0.3 & $\mathrm{ND}^{\mathrm{d}}$ & $\mathrm{ND}$ & ND & ND & 0.3 & 0.1 & 1.6 & ND & 1.7 & 0.1 & 29.5 & ND & 29.6 \\
\hline & 1306 & 1.1 & ND & ND & ND & 36.6 & 37.6 & 0.1 & 1.5 & 0.2 & 1.7 & ND & 15.4 & ND & 15.4 \\
\hline & 2470 & 0.2 & 0.1 & ND & ND & 71.5 & 71.9 & 0.0 & 0.1 & 0.4 & 0.5 & ND & 0.8 & ND & 0.8 \\
\hline & 3003 & 0. & 0.1 & $\mathrm{ND}$ & ND & 80.3 & 80.8 & ND & 0.2 & ND & 0.2 & ND & 0.9 & ND & 0.9 \\
\hline \multirow{4}{*}{$\begin{array}{l}\text { Subsurface } \\
(10-12 \mathrm{~cm})\end{array}$} & 8 & 0 & ND & 7.8 & 1.6 & 2.1 & 11.9 & 0.1 & 1.7 & 0.1 & 1.9 & 0.2 & 27.0 & ND & 27.1 \\
\hline & 1306 & 2.2 & 0.9 & 1.8 & 0.4 & 2.1 & 7.4 & 0.2 & 6.7 & ND & 6.9 & 0.1 & 29.7 & ND & 29.7 \\
\hline & 2470 & 4.3 & 2.7 & ND & ND & 18.6 & 25.6 & 0.1 & 5.8 & ND & 5.9 & ND & 23.2 & ND & 23.2 \\
\hline & 3003 & 9.1 & 3.4 & ND & ND & 13.0 & 25.5 & 0.2 & 4.3 & ND & 4.6 & ND & 21.9 & ND & 21.9 \\
\hline
\end{tabular}

\begin{tabular}{|c|c|c|c|c|c|c|c|c|c|c|c|c|c|c|}
\hline \multirow[b]{2}{*}{ Sediment } & \multirow[b]{2}{*}{$\begin{array}{c}\text { Depth } \\
(\mathrm{m} \text { b.s.l. })\end{array}$} & \multicolumn{4}{|c|}{ GDGT-3 } & \multicolumn{4}{|c|}{ GDGT-4 } & \multicolumn{4}{|c|}{ Crenarchaeol } & \multirow{2}{*}{$\begin{array}{l}\text { IPL abundance } \\
\left(\text { au } \cdot g \text { sed } d^{-1}\right)^{\text {e }}\end{array}$} \\
\hline & & MH & $\begin{array}{c}\text { DH } \\
\mathrm{I}^{\mathrm{b}}\end{array}$ & $\mathrm{HPH}$ & Sum & MH & $\begin{array}{c}\mathrm{DH} \\
\mathrm{I}^{\mathrm{b}}\end{array}$ & HPH & Sum & MH & $\begin{array}{c}\mathrm{DH} \\
\mathrm{I}^{\mathrm{b}}\end{array}$ & $\mathrm{HPH}$ & Sum & \\
\hline \multirow{4}{*}{$\begin{array}{l}\text { Surface } \\
(0-0.5 \mathrm{~cm})\end{array}$} & 885 & ND & 17.8 & ND & 17.8 & ND & 6.1 & ND & 6.1 & 1.3 & 43.1 & 0.3 & 44.6 & $3.3 \mathrm{E}+08$ \\
\hline & 1306 & 0.0 & 6.9 & ND & 6.9 & ND & 2.7 & ND & 2.7 & 1.4 & 15.5 & 18.7 & 35.6 & $2.6 \mathrm{E}+09$ \\
\hline & 2470 & ND & 0.2 & ND & 0.2 & ND & 0.0 & ND & 0.0 & 0.2 & 0.6 & 25.8 & 26.6 & $4.9 \mathrm{E}+09$ \\
\hline & 3003 & ND & 0.4 & ND & 0.4 & ND & 0.0 & ND & 0.0 & 0.4 & 0.2 & 17.1 & 17.6 & $9.4 \mathrm{E}+09$ \\
\hline \multirow{4}{*}{$\begin{array}{l}\text { Subsurface } \\
(10-12 \mathrm{~cm})\end{array}$} & 885 & 0.1 & 15.9 & ND & 15.9 & ND & 9.4 & ND & 9.4 & 1.1 & 31.1 & 1.5 & 33.8 & $5.2 \mathrm{E}+08$ \\
\hline & 1306 & 0.0 & 14.5 & ND & 14.5 & ND & 6.1 & ND & 6.1 & 2.7 & 32.4 & 0.4 & 35.5 & $2.8 \mathrm{E}+08$ \\
\hline & 2470 & ND & 9.6 & ND & 9.6 & ND & 2.9 & ND & 2.9 & 3.5 & 28.3 & 1.0 & 32.8 & $9.4 \mathrm{E}+07$ \\
\hline & 3003 & ND & 9.7 & ND & 9.7 & ND & 5.6 & ND & 5.6 & 8.2 & 23.9 & 0.6 & 32.7 & $1.9 \mathrm{E}+08$ \\
\hline
\end{tabular}

\footnotetext{
${ }^{\mathrm{a}}$ Green colors indicate a low relative abundance; red colors indicate a high relative abundance. ${ }^{\mathrm{b}} \mathrm{DH}$ isomers were detected as a GDGT with a glycosidically bound hexose moiety on both ends of the core (I) and with one glycosidically bound dihexose moiety on one end (II). ${ }^{\mathrm{c}} \mathrm{HCP}$ is an IPL type with an ether-bound cyclopentanetetraol moiety on one end and an hexose moiety on the other (previously reported as GDNT; e.g., De Rosa and Gambacorta, 1988; Sturt et al., 2004)

${ }^{\mathrm{d}} \mathrm{ND}$ : not detected. ${ }^{\mathrm{e}}$ Response area of summed IPLs given in au (arbitrary units) per gram of dry weight (dw) sediment.
}

IPL type DH (all with a hexose molecule on both ends of the CL).

The surface sediment at $1306 \mathrm{mb}$ b.s.l. contained mostly IPL-GDGT-0 (37.6\% of all detected IPL-GDGTs), almost entirely with IPL type HPH (36.6\% of the total; Table 2$)$. Slightly less abundant was the IPL crenarchaeol $(35.6 \%)$, with IPL type HPH (18.7\%) and DH type I (15.5\%) in equal amounts and with a minor relative abundance with MH (1.4\%). Overall, the IPL-GDGTs in surface sediment at $1306 \mathrm{~m}$ b.s.l. mainly contained IPL types HPH (55.4\%; Table 3 ) and DH (42.0\%; Table 3).

Well below the OMZ, surface sediments from 2470 and $3003 \mathrm{~m}$ b.s.l. were both dominated by IPL-GDGT-0 (71.9 and $80.8 \%$ of all detected IPL-GDGTs, respectively), predominantly with IPL type HPH (Table 2; Fig. 1a). The IPL-crenarchaeol had a lower relative abundance (26.6 and $17.6 \%$, respectively) and again was dominated by the member with IPL type HPH (Table 2). The other IPL-GDGTs occurred in minor quantities $(<1 \%)$. Overall, IPL type HPH was, thus, by far the most abundant head group detected in surface sediments at 2470 and 3003 m b.s.l. (97.7 and $97.4 \%$, respectively), in contrast to the other two surface sediments studied (Table 3).

In all subsurface $(10-12 \mathrm{~cm})$ sediments (i.e., at 885,1306 , 2470 and $3003 \mathrm{~m}$ b.s.l.) the most abundant IPL-GDGTs were
Table 3. Relative abundance of IPL-GDGTs grouped by polar head group*.

\begin{tabular}{lrrrrr}
\hline Sample & $\begin{array}{r}\text { Depth } \\
\text { (m b.s.1.) }\end{array}$ & MH & DH & HCP & HPH \\
\hline Surface & 885 & $1.7 \%$ & $98.1 \%$ & $0.0 \%$ & $0.3 \%$ \\
$(0-0.5 \mathrm{~cm})$ & 1306 & $2.6 \%$ & $42.0 \%$ & $0.0 \%$ & $55.4 \%$ \\
& 2470 & $0.5 \%$ & $1.8 \%$ & $0.0 \%$ & $97.7 \%$ \\
& 3003 & $0.8 \%$ & $1.8 \%$ & $0.0 \%$ & $97.4 \%$ \\
\hline Subsurface & 885 & $1.8 \%$ & $92.9 \%$ & $1.6 \%$ & $3.7 \%$ \\
$(10-12 \mathrm{~cm})$ & 1306 & $5.2 \%$ & $91.9 \%$ & $0.4 \%$ & $2.5 \%$ \\
& 2470 & $7.9 \%$ & $72.6 \%$ & $0.0 \%$ & $19.6 \%$ \\
& 3003 & $17.6 \%$ & $68.8 \%$ & $0.0 \%$ & $13.6 \%$ \\
\hline
\end{tabular}

* Polar head group types detected: MH: monohexose; DH: dihexose, both isomers combined; HCP: monohexose and cyclopentanetetraol; HPH: monohexose and phosphohexose.

DH-crenarchaeol (28.9 $\pm 3.8 \%$; Table 2) and DH-GDGT-2 $(25.5 \pm 3.5 \%$; Table 2$)$. DH was also the most commonly observed IPL type attached to GDGT-3 and GDGT-4 (Table 2). Overall the distributions of the IPL-GDGTs in all subsurface sediments were relatively similar (Fig. 1a) in comparison to the substantial changes observed at the surface (cf. Fig. 1a). Overall, the DH IPL type was the predom- 


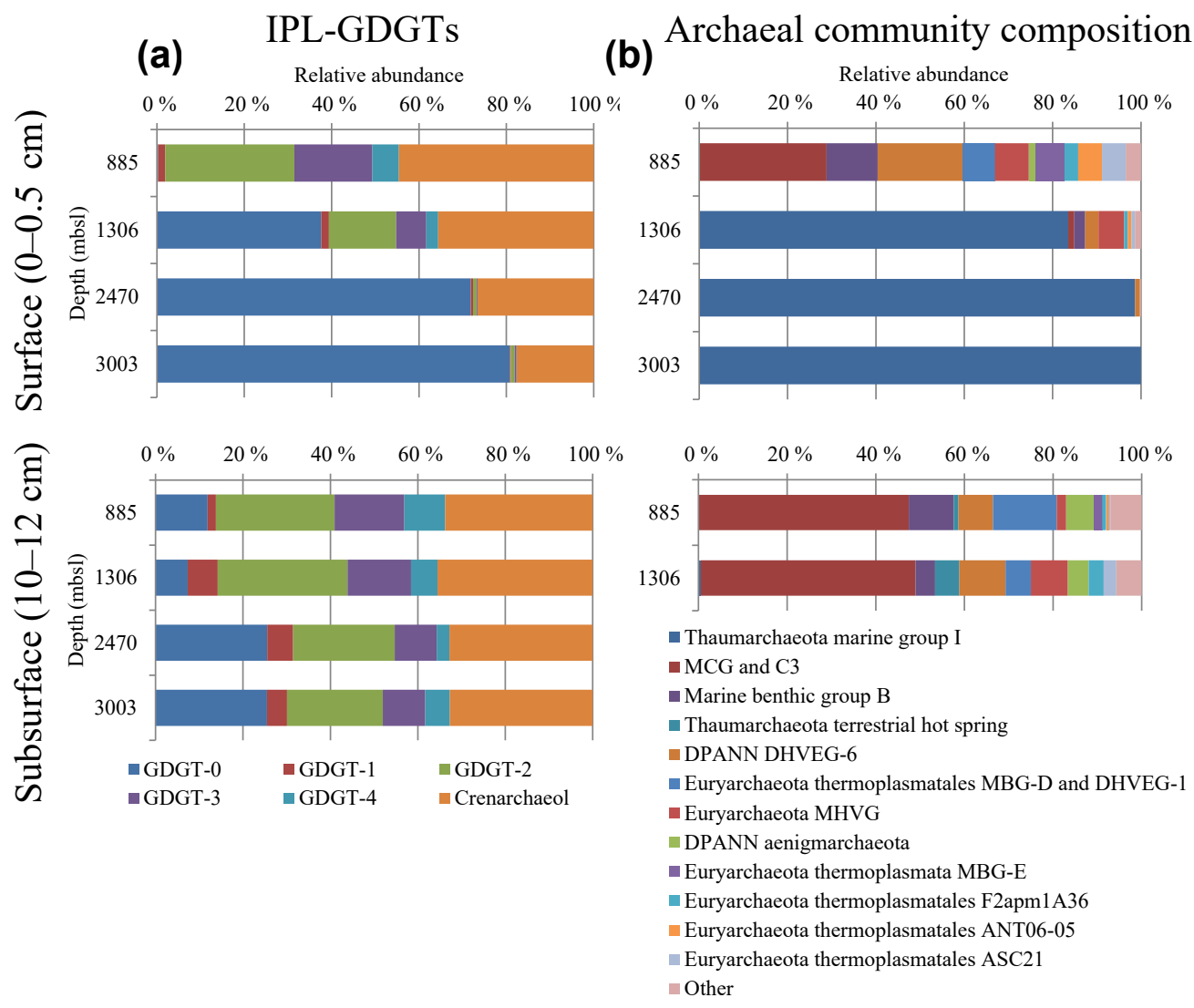

Figure 1. (a) Relative abundances of the IPL-GDGTs (sum of IPL types MH, DH and HPH) for the different core GDGTs in the surface $(0-0.5 \mathrm{~cm})$ and subsurface sediments $(10-12 \mathrm{~cm})$ and $(\mathbf{b})$ the archaeal community composition as revealed by $16 \mathrm{~S}$ rRNA gene reads (with average abundance above of $>1 \%$ ) in the surface sediments at $885,1306,2470$, and $3003 \mathrm{~m}$ b.s.l. and in the subsurface sediments at 885 and $1306 \mathrm{~m}$ b.s.l.

inant one detected in subsurface sediment, with a relative abundance ranging from $68.8 \%$ at $3003 \mathrm{~m}$ b.s.1. to $92.9 \%$ at $885 \mathrm{~m}$ b.s.l. (Table 3 ). In contrast to all other sediments, in the subsurface sediments at 885 and $1306 \mathrm{~m}$ b.s.l., two different isomers (Fig. S2) of the DH-GDGT-0 were detected (Table 2). DH type-I (0.9\% at $1306 \mathrm{~m}$ b.s.l.) is also found in the other surface and subsurface sediments and in combination with other core GDGT structures, whereas the other isomer (DH type-II) only occurs in subsurface sediments at 885 and $1306 \mathrm{~m}$ b.s.l. (7.8\% at $885 \mathrm{~m}$ b.s.l., $1.8 \%$ at $1306 \mathrm{~m}$ b.s.l.; Table 2; Fig. S2b). In addition, these subsurface sediments also contain small amounts of GDGT- 0 with cyclopentanetetraol and $\mathrm{MH}$ head groups (IPL type HCP; $1.6 \%$ at $885 \mathrm{mb}$ b.s.l; $0.4 \%$ at 1306 m b.s.1.; Table 2; Fig. S2c).

We also determined the IPL-derived CL-GDGTs in the $885 \mathrm{~m}$ b.s.l. surface sediment following the method of Lengger et al. (2012), in order to exclude IPL degradation within the stored samples. The CL-GDGT composition derived from freshly obtained IPL showed the same distribution $(r=0.99, \rho<0.001)$ as reported previously (Lengger et al., 2012).

\subsection{Archaeal diversity in the surface and subsurface sediment}

Different archaeal groups were detected in surface and subsurface sediment across the Arabian Sea OMZ. The surface sediment at $885 \mathrm{~m}$ b.s.l. contained archaeal 16S rRNA gene sequences that were assigned to several archaeal groups (Fig. 1b). The most dominant group was MCG (total $30.5 \%$, $12.2 \%$ attributed to C3; also known as MCG-15, Kubo et al., 2012). Another major group found was the DPANN Woesearchaeota Deep sea Hydrothermal Vent Group 6 (DHVEG6, 20.3\%; Fig. 1b; Castelle et al., 2015). Marine Benthic Groups (MBG) -B, -D and -E were also present, with 12.2, 7.7 and $6.9 \%$ of the archaeal 16S rRNA gene reads, respectively (Fig. 1b). Sequences affiliated with the Marine Hydrothermal Vent Group (MHVG, $8.1 \%$ ) of the phylum Euryarchaeota were also detected (Fig. 1b). Other groups, with lower relative abundances, were Thermoplasmatales groups ANT06-05 (5.7\%) and F2apm1 A36 (3.3\%) and the DPANN Aenigmarchaeota (previously named Deep Sea Euryarchaeotic Group, DSEG; 1.6\%; Fig. 1b). 
Below the $\mathrm{OMZ}$, in partly and fully oxygenated surface sediments at 1306, 2470 and $3003 \mathrm{mb}$ b.s.l. (Table 1), the most dominant archaeal group was Thaumarchaeota MGI, with relative abundances of $81.5,89.7$ and $100 \%$, respectively (Fig. 1b). At $1306 \mathrm{mb}$.s.l. other archaeal groups such as MHVG (5.6\%), Thermoplasmatales ASC21 (3.2\%), DHVEG-6 (2.9\%), MBG-B (2.4\%) and MCG (1.3\%) made up the rest of the archaeal community (Fig. 1b). At 2470 m b.s.1. DHVEG-6 (1.1\%) was still detectable besides the MG-I (Fig. 1b).

In the subsurface sediments $(10-12 \mathrm{~cm})$, only the DNA extracted from the sediments at 885 and $1306 \mathrm{mb}$ b.l. gave a positive amplification signal. The archaeal composition of the subsurface $(10-12 \mathrm{~cm})$ sediments at 885 and $1306 \mathrm{~m}$ b.s.1. was similar (Fig. 1b; Pearson correlation coefficient of 0.95), with most of the $16 \mathrm{~S}$ rRNA gene reads classified within the MCG (47.5 and 48.4\%, respectively). Other archaeal groups, such as MBG-D (14.4 and $5.7 \%$, respectively), MBG-B (10.1 and 4.4\%), and the Woesearchaeota (7.8 and $10.4 \%$ ), were also detected with comparable relative abundances (Fig. 1b). Other archaeal groups such as Thaumarchaeota Terrestrial hot spring, the Euryarchaeota MHVG, MBG-E and the Aenigmarchaeota were detected, but at low $(<10 \%)$ relative abundance (Fig. 1b). Only a minor number of reads were classified as Thaumarchaeota MG-I $(0.5 \%$ at 1306 m b.s.1.) (Fig. 1b).

Considering the high relative abundance of the MCG detected in the surface sediment at $885 \mathrm{mb}$ b.s.l, as well as in the subsurface (10-12 cm) sediments at 885 and $1306 \mathrm{~m}$ b.s.l. (between 30.5 and $48.4 \%$ of total archaeal 16S rRNA gene reads detected in those samples), we performed phylogenetic analyses to determine the diversity of subgroups of the MCG within these sediments. A total of 57 representative 16S rRNA gene reads assigned to MCG were extracted from the dataset and incorporated into a MCG phylogenetic tree of Fillol et al. (2015) (Fig. 2). The majority of MCG 16S rRNA gene reads from the $885 \mathrm{~m}$ b.s.l. surface sediment $(77.3 \%$; Table 4) clustered in subgroup 15 . In the $885 \mathrm{~m}$ b.s.l. subsurface sediment, the majority of MCG reads clustered within subgroups 8 and 15 (33.6 and 19.6\%, respectively; Table 4). In the $1306 \mathrm{~m}$ b.s.l. surface sediment there was only a low relative abundance of MCG (Fig. 1b); all MCG archaea detected clustered in subgroup 15 (Table 4). On the other hand, in the $1306 \mathrm{~m}$ b.s.l. subsurface sediment the reads clustered in subgroups 15,2 and 14 (34.3, 10.9 and $10.9 \%$, respectively; Fig. 2).

As the Thaumarchaeota MG-I was dominant in oxygenated sediments at 1306, 2470 and $3003 \mathrm{~m}$ b.s.l. (Fig. 1b), we further analyzed the diversity of this group by performing a more detailed phylogeny of the recovered 16S rRNA gene reads attributed to this group. Five OTUs dominated the Thaumarchaeota MG-I (Table 5); we will refer to them as OTU-1 to -5 . OTU-1, $-2,-3$ and -5 were phylogenetically closely related to other known benthic Thaumarchaeota MGI species, such as "Ca. Nitrosoarchaeum koreensis MY1" or
Table 4. Relative abundance (in \%) of MCG- and C3-assigned 16S rRNA gene reads relative to total archaeal reads and distribution (in $\%$ ) of various subgroups for a station within and a station just below the OMZ.

\begin{tabular}{lrr|rr}
\hline & \multicolumn{2}{c|}{$885 \mathrm{~m}$ b.s.1. } & \multicolumn{2}{c}{$1306 \mathrm{~m}$ b.s.1. } \\
\cline { 2 - 5 } Subgroup & $\begin{array}{r}\text { Surface } \\
(0-0.5 \mathrm{~cm})\end{array}$ & $\begin{array}{r}\text { Subsurface } \\
(10-12 \mathrm{~cm})\end{array}$ & $\begin{array}{r}\text { Surface } \\
(0-0.5 \mathrm{~cm})\end{array}$ & $\begin{array}{r}\text { Subsurface } \\
(10-12 \mathrm{~cm})\end{array}$ \\
\hline Total & 30.5 & 47.5 & 1.3 & 48.8 \\
\hline 1 & & 4.6 & & 8.6 \\
2 & & 9.7 & & 10.9 \\
3 & & $<1$ & & 2.3 \\
4 & & $<1$ & & \\
$5 \mathrm{~b}$ & & $<1$ & & 10.3 \\
8 & 2.3 & 33.6 & & 4.0 \\
10 & & 13.4 & & 8.0 \\
12 & 13.6 & 7.7 & & 2.3 \\
13 & & 1.2 & & 10.9 \\
14 & 2.3 & 3.1 & & 34.3 \\
15 & 77.3 & 19.6 & 100 & 8.6 \\
17 & 4.5 & 5.7 & & \\
\hline
\end{tabular}

Table 5. Total Thaumarchaeota MG-I 16S rRNA gene reads and distribution per OTU (\%) in surface sediments.

\begin{tabular}{lrrrr}
\hline & \multicolumn{4}{c}{ Depth (m b.s.l.) } \\
\cline { 2 - 5 } & 885 & 1306 & 2470 & 3003 \\
\hline Total reads & 0 & 915 & 1341 & 1305 \\
OTU ID no. 1 & $\mathrm{n} / \mathrm{a}$ & 4.3 & 2.5 & 3.0 \\
OTU ID no. 2 & $\mathrm{n} / \mathrm{a}$ & 3.9 & 8.1 & 13.6 \\
OTU ID no. 3 & $\mathrm{n} / \mathrm{a}$ & 43.6 & 67.6 & 61.8 \\
OTU ID no. 4 & $\mathrm{n} / \mathrm{a}$ & 35.1 & 1.6 & 0 \\
OTU ID no. 5 & $\mathrm{n} / \mathrm{a}$ & 3.3 & 4.7 & 2.1 \\
\hline
\end{tabular}

n/a - not applicable.

environmental 16S rRNA gene sequences from marine sediments (Fig. 3). On the other hand, OTU-4 clustered with $16 \mathrm{~S}$ rRNA gene sequences from pelagic Thaumarchaeota MGI species, like Ca. Nitrosopelagicus brevis, and also clustered with $16 \mathrm{~S}$ rRNA sequences recovered from seawater SPM (Fig. 3). OTU-3 was the most abundant OTU in the surface sediment at 1306, 2470, and $3003 \mathrm{~m}$ b.s.l. with a relative abundance of 44-68\% (Table 5). At $1306 \mathrm{~m}$ b.s.l. OTU4 was the second most abundant $(35.1 \%)$. This OTU had a much lower relative abundance $(1.6$ and $0.0 \%$ ) at 2470 and $3003 \mathrm{~m}$ b.s.1., respectively (Table 5). The relative abundance of OTU-2 increased with increasing sampling station depth (Table 5), OTU-1 and -5 had an abundance $<5 \%$ in the surface sediments (Table 5).

The diversity of Thaumarchaeota MG-I was further assessed by amplification, cloning and sequencing of the archaeal amoA gene. Most of the amoA gene sequences from surface (27 out of 29 clones) and subsurface sediment at $885 \mathrm{~m}$ b.s.l. (9 out of 10 clones) and just one from the sur- 


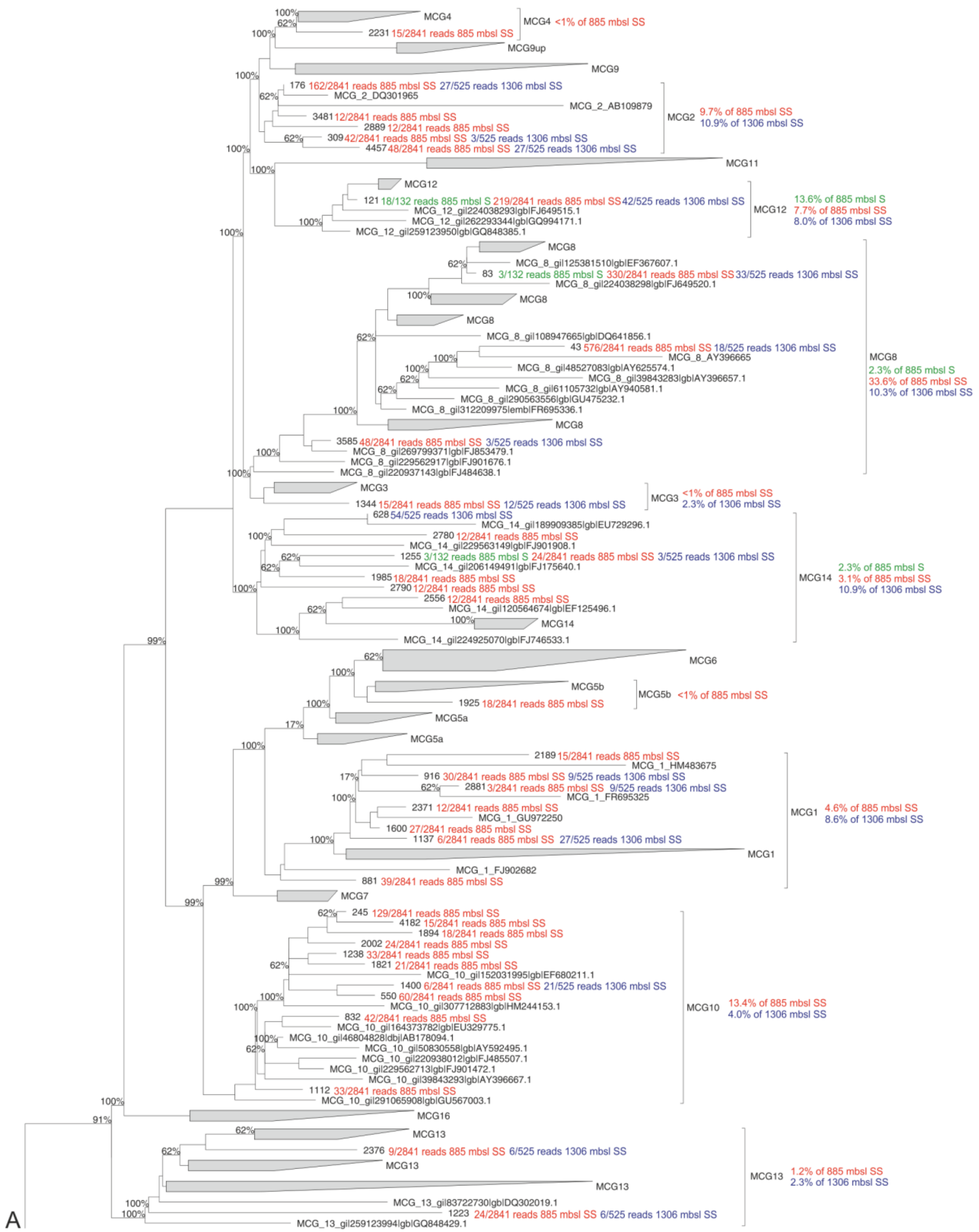

0.02

Figure 2. 


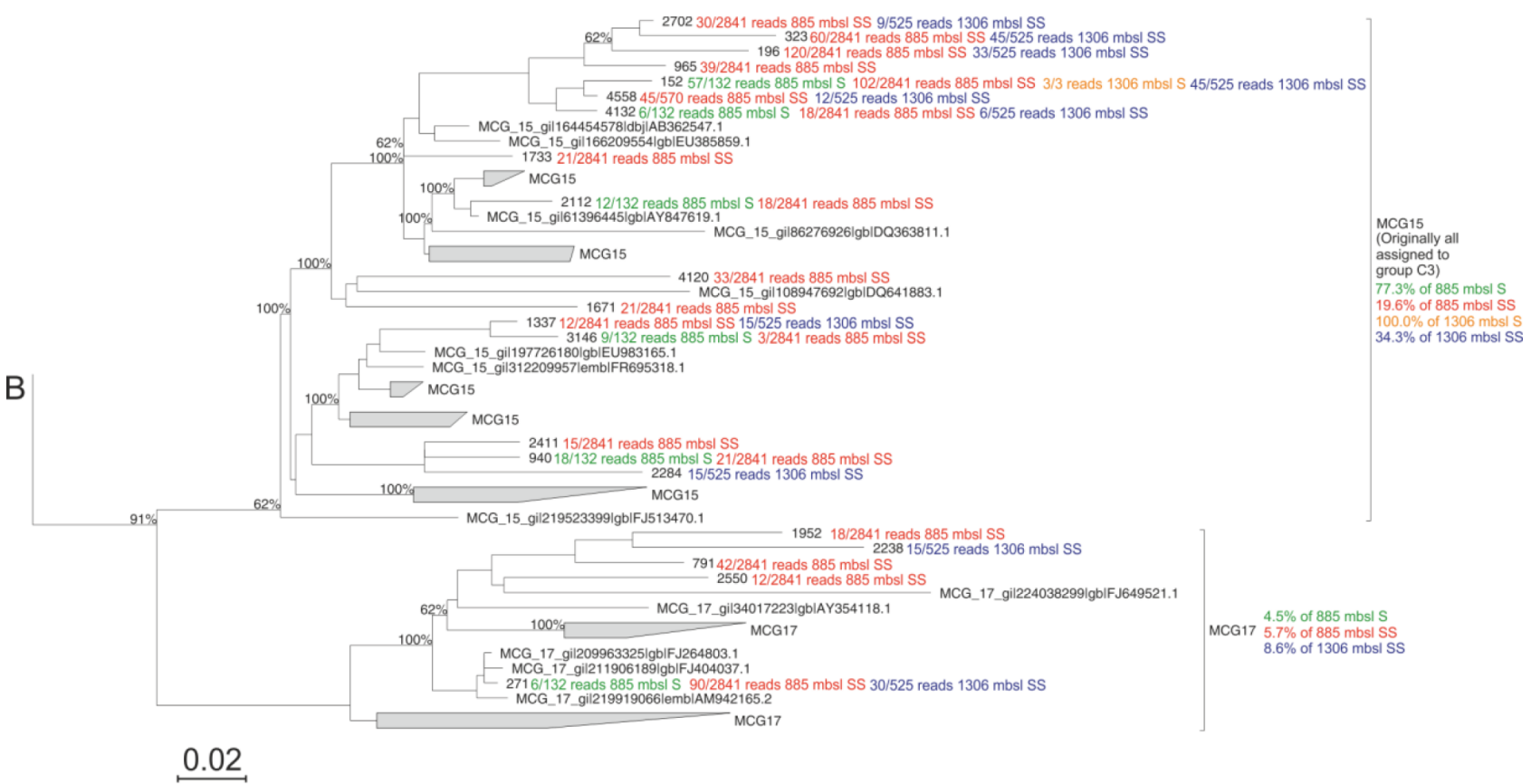

Figure 2. Maximum likelihood phylogenetic tree of the archaeal groups MCG and C3 (modified from Fillol et al., 2015). Extracted OTUs from the Arabian Sea sediments assigned as MCG were inserted in the tree. The number of detected reads per OTU per sample are indicated. Per MCG subgroup the relative abundance is given as detected at the different stations and sediment depths; this is also noted in Table 4. The scale bar represents a $2 \%$ sequence dissimilarity.

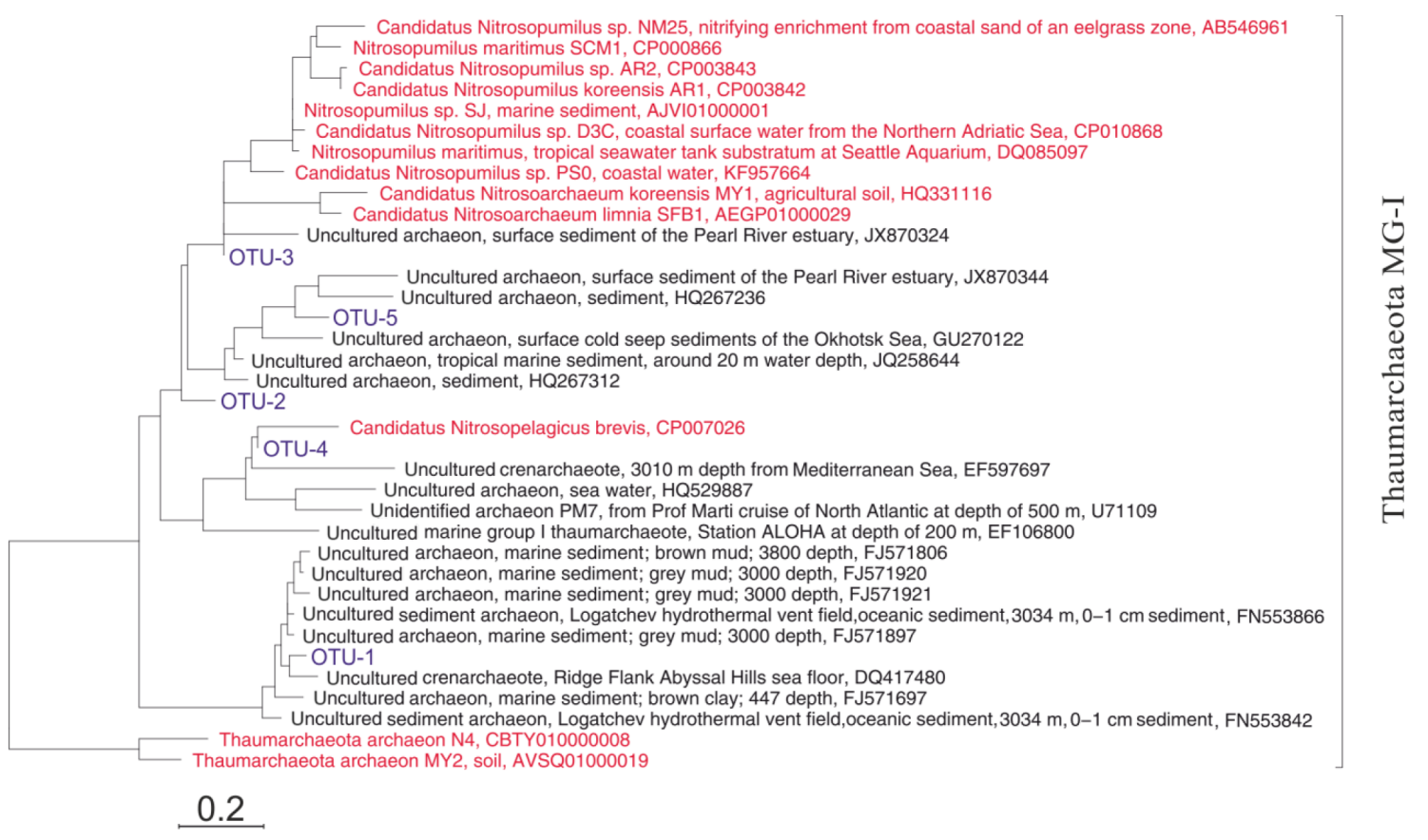

Figure 3. Maximum likelihood phylogenetic tree of MG-I OTUs recovered within the sediment based on the 16S rRNA gene (colored in blue). Sequences from cultured representatives of Thaumarchaeota MG-I are indicated in red. Environmental sequences of MG-I members are indicated in black with their origin specified. The relative abundances of the various OTUs are listed in Table 4 . The scale bar represents a $2 \%$ sequence dissimilarity. 


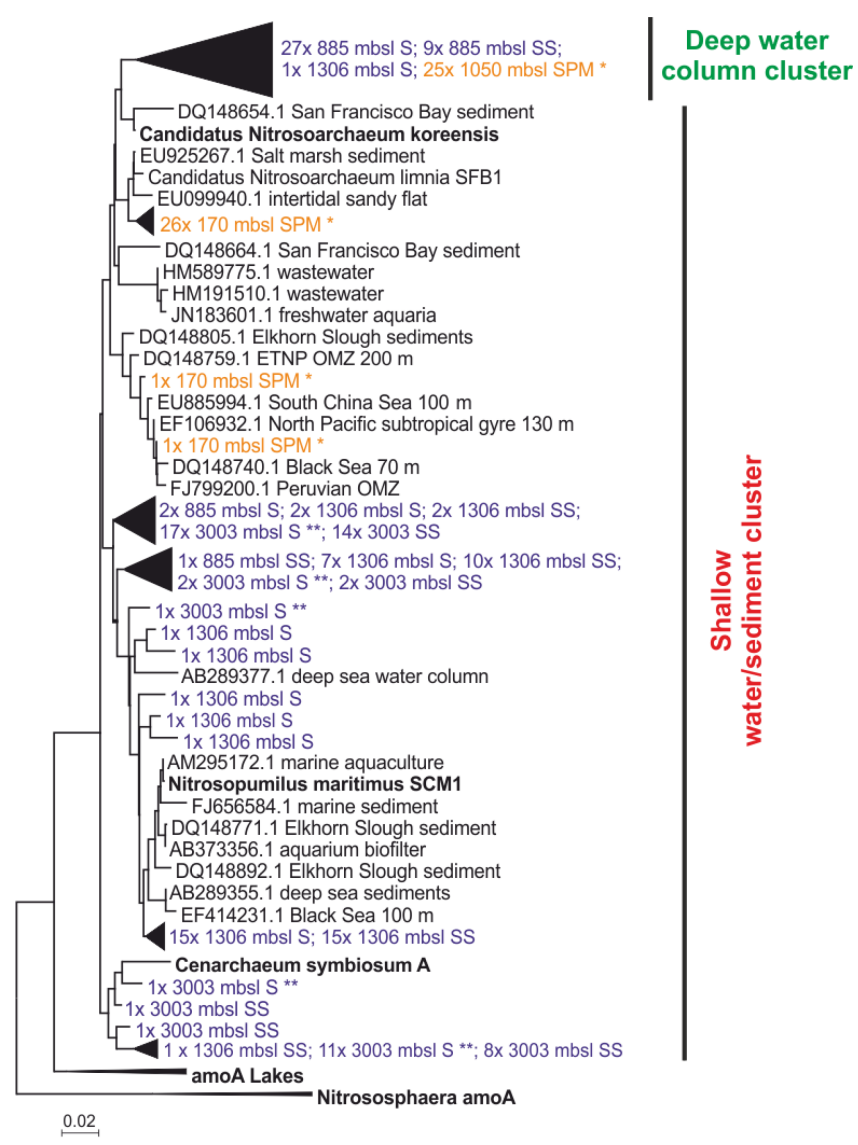

Figure 4. Maximum likelihood phylogenetic tree of amoA gene coding sequences recovered from surface $(\mathrm{S} ; 0-0.5 \mathrm{~cm})$ and subsurface (SS; 10-12 cm) sediments (colored in blue) at 885, 1306 and $3003 \mathrm{~m}$ b.s.l. (155 clones). AmoA gene coding sequences recovered from SPM (colored in orange) at $170 \mathrm{mb}$ b.s. (28 clones); SPM at $1050 \mathrm{~m}$ b.s.l. (25 clones) reported by Villanueva et al. (2014). ${ }^{* *}$ indicates amoA gene sequences recovered from surface sediments at $3003 \mathrm{~m}$ b.s.l. previously reported in Villanueva et al. (2014). The scale bar represents a $2 \%$ sequence dissimilarity.

face sediment from $1306 \mathrm{~m}$ b.s.l. (1 out of 58 clones) were closely related to amoA gene sequences previously recovered from SPM at $1050 \mathrm{~m}$ b.s.l. from this area of the Arabian Sea (Villanueva et al., 2014). Phylogenetically they fall within the "Water column B, subsurface water" amoA clade as defined by Francis et al. (2005) (Fig. 4). At 1306 and $3003 \mathrm{~m}$ b.s.l. (surface and subsurface) the majority of recovered $a m o \mathrm{~A}$ gene sequences clustered within the "shallow water/sediment" clade (100 and $98.3 \%$, respectively) and are closely related to amoA gene sequences from water column SPM at $170 \mathrm{~m}$ b.s.l. (Villanueva et al., 2014) as well as amoA gene coding sequences previously detected in sediments (Villanueva et al., 2014; Fig. 4). Of all recovered amoA gene sequences from $885 \mathrm{~m}$ b.s.l. only a small fraction (8.3\%) clustered within the "shallow water/sediment" clade (Fig. 4).

\subsection{Abundance and potential activity of archaea in surface and subsurface sediments}

The abundance of archaeal 16S rRNA gene copies in the surface sediments of different stations varied slightly: it was lowest at $1306 \mathrm{~m}$ b.s.l. $\left(9.8 \times 10^{9}\right.$ copies $\mathrm{g}^{-1}$ sediment $)$ and highest at $2470 \mathrm{~m}$ b.s.l. $\left(1.5 \times 10^{11}\right.$; Fig. $\left.5 \mathrm{a}\right)$. The potential activity, based on the 16S rRNA gene transcripts of the archaeal 16S rRNA gene, was the lowest at $2470 \mathrm{~m}$ b.s.l. $\left(5 \times 10^{4}\right.$ transcripts $\mathrm{g}^{-1}$ sediment $)$, while a higher potential activity was detected at 885,1306 and $3003 \mathrm{~m}$ b.s.l. (0.9$42 \times 10^{7}$; Fig. 5a). The abundance of archaeal $16 \mathrm{~S}$ rRNA gene copies in the subsurface sediment varied also within 1.5 orders of magnitude $\left(1.1-54 \times 10^{9}\right.$; Fig. 5c), with a decrease with increasing water depth. The potential activity showed less variation within the subsurface sediments $\left(1.2-22 \times 10^{7} 16 \mathrm{~S}\right.$ rRNA gene transcripts $\mathrm{g}^{-1}$ of sediment; Fig. 5c) than in the surface sediments.

The abundance of Thaumarchaeota was estimated by quantifying the archaeal amoA gene copies. The highest abundance of amoA gene copies in surface sediment was detected at $2470 \mathrm{mb}$ b.s.l. $\left(1.0 \times 10^{9}\right.$ copies $^{-1}$ sediment $)$, and the lowest at $885 \mathrm{mb}$ b.s.l. $\left(5 \times 10^{4}\right.$; Fig. $\left.5 \mathrm{~b}\right)$. AmoA gene transcripts in surface sediment were under the detection limit at $885 \mathrm{~m}$ b.s.l. but were detected below the OMZ with $4 \times 10^{2}, 2.3 \times 10^{6}$ and $8 \times 10^{3}$ gene transcripts $\mathrm{g}^{-1}$ of sediment at 1306, 2470 and $3003 \mathrm{~m}$ b.s.l., respectively (Fig. 5b). In subsurface sediments, the abundance of amoA gene copies was low at 885 and $1306 \mathrm{mb}$ b.s.l. $\left(5.4-19 \times 10^{2}\right.$ gene transcripts $\mathrm{g}^{-1}$ sediment) and higher at 2470 and $3003 \mathrm{~m}$ b.s.l. $\left(4.1 \times 10^{5}, 5.4 \times 10^{6}\right.$, respectively; Fig. 5 d). AmoA gene transcripts were not detected in the subsurface sediments (Fig. 5d).

\section{Discussion}

In this study, we assessed the changes in benthic archaeal diversity and abundance in sediments of the Arabian Sea oxygen minimum zone along a gradient in bottom water oxygen concentrations. The steep Murray Ridge protrudes into the OMZ, allowing the study of sediments deposited under varying bottom water oxygen concentrations. All these sediments receive organic matter $(\mathrm{OM})$, the most important fuel for benthic prokaryotic activity in sediments. This OM is produced in a relatively small area of the ocean (i.e., the stations within the OMZ, at $885 \mathrm{~m}$ b.s.l., and well below the OMZ, at $3003 \mathrm{~m}$ b.s.l., are only $110 \mathrm{~km}$ apart) and, therefore, is likely composed of the same primary photosynthate. However, due to differences in the degree of mineralization resulting from different exposure to oxic conditions in the water column, there were differences in $\mathrm{OM}$ quality. $\mathrm{OM}$ in the sediments within the OMZ has a higher biochemical "quality" based on amino acid composition and intact phytopigments compared to OM in the sediments below the OMZ (Koho et al., 2013). 

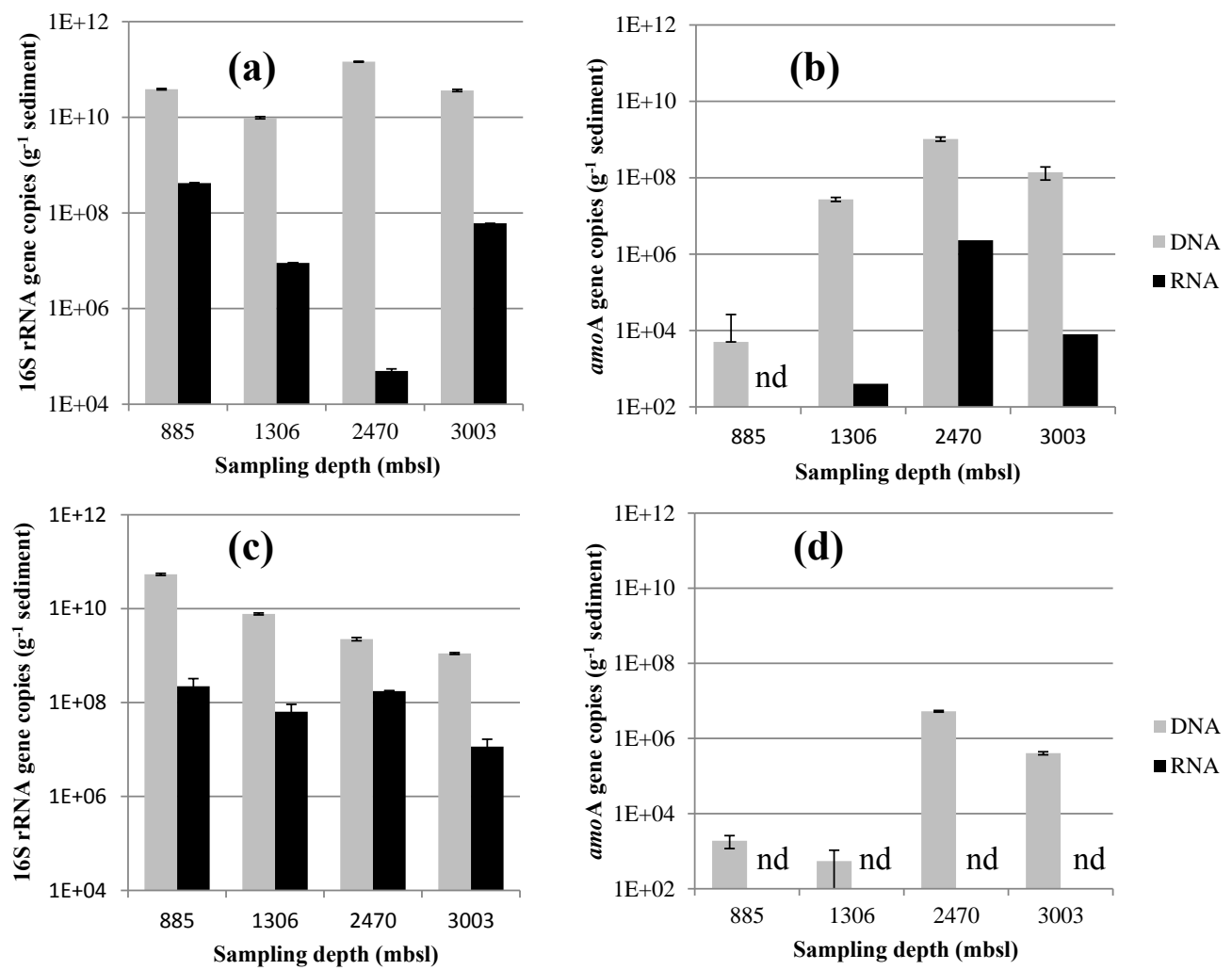

Figure 5. Abundance of Thaumarchaeotal 16S rRNA (a, c) and amoA (b, d) gene fragment copies per gram of dry weight in the surface sediment $(0-0.5 \mathrm{~cm})(\mathbf{a}, \mathbf{b})$ and the subsurface sediment $(10-12 \mathrm{~cm})(\mathbf{c}, \mathbf{d})$. Black bars indicate the number of DNA 16S rRNA or amoA gene fragment copies and the gray bars indicate the RNA (gene transcripts) of 16S rRNA or amoA gene fragment copies. Error bars indicate standard deviation based on $n=3$ experimental replicates.

Therefore, changes in the quality and flux of OM received by the different sediment niches could also affect the archaeal community composition as several of the archaeal groups (i.e., MCG and MBG-D) reported here have been suggested to use $\mathrm{OM}$ as a carbon source in anoxic conditions (Lloyd et al., 2013).

\subsection{Effect of oxygen availability on archaeal diversity and abundance in the surface sediments}

We detected large differences in archaeal diversity between the surface sediment deposited within the OMZ and those deposited below the OMZ. In contrast to the diverse anaerobic archaeal community in the surface of $885 \mathrm{mb}$ b.s.l., in surface sediments at 1306, 2470 and $3003 \mathrm{~m}$ b.s.l., Thaumarchaeota MG-I were dominant, representing $80-100 \%$ of the archaeal population (Fig. 1). This clear difference in the benthic archaeal population in the surface sediments can be attributed to the oxygen availability as Thaumarchaeota are known to require oxygen for their metabolism (i.e., nitrification; Könneke et al., 2005). In fact, the oxygen penetration depth (OPD) was observed to be 3,10 , and $19 \mathrm{~mm}$ in sediments at 1306, 2470, and $3003 \mathrm{~m}$ b.s.l., respectively, while in sediments at $885 \mathrm{mb}$ b.s.l., the OPD was barely $0.1 \mathrm{~mm}$ (Table S1; Kraal et al., 2012). The surface $(0-5 \mathrm{~mm})$ sediment at $1306 \mathrm{mb}$ b.s.l. was not fully oxygenated (OPD of $3 \mathrm{~mm}$ ), which probably explains the detection in relatively low abundance (ca. $20 \%$ ) of the anaerobic archaea that thrive in the anoxic sediment from $885 \mathrm{~m}$ b.s.l. The low OPD at $1306 \mathrm{~m}$ b.s.l. also explains the low amoA gene expression in comparison with the deeper surface sediments (Fig. 5b, d). Overall this indicates the presence of Thaumarchaeota with lower activity in the surface sediments at $1306 \mathrm{~m}$ b.s.l. (Fig. 5). Within the Thaumarchaeota MG-I group, we also detected changes in the relative abundance of specific OTUs in the surface sediments at 1306, 2470 and $3003 \mathrm{~m}$ b.s.l. (Table 5). For example, OTU-2 becomes progressively more abundant with increasing water depth, suggesting that this OTU is favored at the higher oxygen concentrations found in the surface sediment at $3003 \mathrm{mb}$ b.s.l. OTU-4 was closely affiliated with "Ca. Nitrosopelagicus brevis", a pelagic MG-I member, which indicates that this DNA is most likely derived from the overlying water column (Table 5), and thus should be considered to represent fossil DNA.

High amoA gene abundances were detected in the surface sediment at 2470 and $3003 \mathrm{~m}$ b.s.l., while values in the sur- 
face of $885 \mathrm{~m}$ b.s.l. were approximately 3 orders of magnitude less. The lack of oxygen in the surface sediments at $885 \mathrm{~m}$ b.s.l. and in the subsurface sediments, as well as undetectable amoA gene transcripts at those depths, suggest that in these cases the amoA gene DNA signal is fossil. It is well known that under anoxic conditions DNA of marine pelagic microbes may become preserved in sediments even for periods of thousands of years (Boere et al., 2011; Coolen et al., 2004b). The fossil origin of the Thaumarchaeotal amoA gene is supported by the phylogenetic affiliation of the amoA gene fragments amplified from the $885 \mathrm{~m}$ b.s.l. surface sediment, as those sequences were closely related to amoA gene sequences detected in the suspended particulate matter in the subsurface water column (Villanueva et al., 2014), thus suggesting that the detected DNA originated from pelagic Thaumarchaeota present in the subsurface water column, as proposed for the presence of OTU-4 16S rRNA gene sequences in the surface sediment (see earlier).

There is a discrepancy between the 16S rRNA gene copy numbers and the amoA gene copy numbers within the sediments (Fig. 5). AmoA gene copies were consistently lower than the 16S rRNA gene copies, even within sediments that were completely dominated by Thaumarchaeota MG-I. This may be caused by the amoA gene primer mismatches and/or the disparity of gene copy numbers within the archaeal genomes (Park et al., 2008).

In the anoxic surface sediment at $885 \mathrm{mb}$ b.s.l. (within the OMZ), we detected a highly diverse archaeal population composed of MCG, Thermoplasmatales, MBG-B, -D and -E, Woesearchaeota, and MHVG. Archaeal groups such as MCG and MBG-B and -E have been previously described in anoxic marine sediments, where they have been suggested to be involved in anaerobic OM degradation (e.g., Biddle et al., 2006; Inagaki et al., 2003; Castelle et al., 2015). Members of the DPANN Woesearchaeota were only present in the surface sediment at $885 \mathrm{~m}$ b.s.l. but not in the subsurface anoxic sediments at 885 and $1306 \mathrm{~m}$ b.s.l., suggesting that their presence here is not solely dependent on the absence of oxygen but possibly also on the OM composition and availability in surface and subsurface sediments. Alternatively, the DPANN Woesearchaeota 16S rRNA gene signal could also originate from the water column and be deposited in the surface sediment at $885 \mathrm{~m}$ b.s.l. as fossil DNA as observed for the case of Thaumarchaeota as mentioned above.

\subsection{Archaeal community composition in the anoxic subsurface sediments}

The archaeal diversity in the subsurface sediment $(10-12 \mathrm{~cm})$ from both 885 and $1306 \mathrm{~m}$ b.s.l. (i.e., dominated by MCG and MBG-B, -D and -E) is similar to that observed in the surface sediment at $885 \mathrm{~m}$ b.s.l. This supports oxygen availability being an important factor in determining the diversification of archaeal groups (Fig. 1b). MCG, one of the dominant archaeal groups in these sediments, showed sub- stantial differences in the distribution of its subgroups (Table 4). All subsurface sediments had a high intra-group diversity of MCG. This is in contrast with the surface sediment at 885 and $1306 \mathrm{~m}$ b.s.l. where a high relative abundance of subgroup MCG-15 is detected (Table 4). A recent study with enrichments of estuarine sediments showed evidence that MCG-8 is capable of growth with lignin as an energy source (Yu et al., 2018). MCG-8 was the most or one of the most abundant MCG groups in our studied subsurface sediments (Table 4). Substantial lignin concentrations were previously not detected in the Arabian Sea, which indicated a relatively invariant terrestrial OM contribution (Cowie et al., 1999). Therefore it remains uncertain which physicochemical factor(s) influence the MCG-8 subgroup in the studied subsurface sediments. A recent survey of the ecological niches and substrate preferences of the MCG in estuarine sediments based on genomic data pointed to MCG-6 archaea as degraders of complex extracellular carbohydrate polymers (plant-derived), while subgroups $1,7,15$ and 17 have mainly the potential to degrade detrital proteins (Lazar et al., 2016). Lazar et al. (2016) also described the presence of aminopeptidases coded in the genome bin of MCG-15, suggesting that this subgroup could be specialized in degradation of extracellular peptides in comparison with the other MCG subgroups, which would be restricted to the use of amino acid and oligopeptides. Considering the dominance of the MCG-15 subgroup in the surface sediments analyzed in this study (Table 4), we hypothesize that the proteinaceous OM deposited in the surface sediment, which mainly originates from photosynthate, is still quite undegraded. This would favor the MCG-15 in this niche, fueling its metabolism by the degradation of peptides extracellularly, while in subsurface sediments, other MCG groups such as 2, 8 and 14 would be more favored.

The archaeal 16S rRNA gene abundance in the subsurface sediments progressively declined with increasing water depth, while the potential activity was similar. This can be due to the expected decrease in the flux of OM being delivered to these anoxic sediment layers attributed to higher degradation of OM in oxygenated bottom waters and the progressively larger oxic zone in the sediments (Lengger et al., 2012; Nierop et al., 2017). This results in lower organic carbon concentrations and a decreased biochemical quality of the OM (Koho et al., 2013; Nierop et al., 2017) to sustain the heterotrophic archaeal population inhabiting the anoxic subsurface sediments. Also, the presence or lack of macrofauna in the analyzed sediments would have an effect on the OM composition; sediments within the OMZ are less prone to bioturbation, which most likely resulted in higher OM preservation (Koho et al., 2013). Differences in the OM biochemical composition can influence the microbial community composition, as was shown recently for North Sea sediments (Oni et al., 2015). 


\subsection{Benthic archaea as potential sources for archaeal IPLs}

Archaeal lipids in surface and deeper sediments of the Murray Ridge (Lengger et al., 2012, 2014), as well as in the overlaying water column (Pitcher et al., 2011; Schouten et al., 2012), were studied earlier. The study by Lengger et al. (2012) was limited to the determination of MH-, DHand HPH-crenarchaeol with HPLC/ESI-MS ${ }^{2}$ using a specific selected reaction monitoring method (SRM; Pitcher et al., 2011). A follow-up study of Lengger et al. (2014) reported MH-, DH- and HPH-IPLs with multiple CL-GDGTs. In our study, we expanded the screening for IPLs carrying different polar head groups in combination with multiple CLs using high-resolution accurate mass/mass spectrometry (see Table S1). By applying this method, we were able to target a broader range of IPLs in these sediments. This allows a more direct comparison with the archaeal diversity detected by gene-based methods. Note that the study of Lengger et al. (2014) used a different sampling resolution (surface sediment used was $0-2 \mathrm{~cm}$ compared to our $0-0.5 \mathrm{~cm}$ ) and our results can, therefore, not be directly compared.

The fully oxygenated surface sediments showed a dominance of GDGT-0 and crenarchaeol mostly with HPH as IPL type (Table 2). This is the expected IPL-GDGT signature of Thaumarchaeota as previously observed in pure cultures (Elling et al., 2017; Pitcher et al., 2010; Schouten et al., 2008; Sinninghe Damsté et al., 2012). The predominance of the HPH IPL type in surface $(0-2 \mathrm{~cm})$ sediments was previously interpreted as an indication of the presence of an active Thaumarchaeotal population synthesizing membrane lipids in situ (Lengger et al., 2012, 2014), taking into account the labile nature of sedimentary phospholipids (Harvey et al., 1986; Schouten et al., 2010; Xie et al., 2013). Elling et al. (2014) showed, in a Thaumarchaeota culture experiment, that a high HPH-crenarchaeal abundance was an indication of metabolically active Thaumarchaeota. The hypothesis by Lengger et al. $(2012,2014)$ is strongly supported by our data because (i) the archaeal community in the oxygenated surface $(0-0.5 \mathrm{~cm})$ sediments is dominated by Thaumarchaeota (Fig. 1) and (ii) the high abundance of thaumarchaeotal amoA gene copies and gene transcripts detected in the oxygenated surface sediments. On the other hand, in the anoxic surface sediment at $885 \mathrm{~m}$ b.s.l., crenarchaeol was predominantly present with DH as the predominant IPL type (Table 2). This is considered to be a fossil signal of Thaumarchaeota deposited from the water column due to a higher preservation potential of glycolipid head groups (as present in DH) as previously suggested (Lengger et al., 2012, 2014). Xie et al. (2013) showed a high preservation potential for glyosidic ether lipids in a 300-day incubation study. However, the differences in degradation rates between phospholipid versus glycolipid GDGTs still need to be determined, especially on longer timescales that apply to sediments. Nevertheless, the presence of amoA gene se- quences in the $885 \mathrm{~m}$ b.s.l. surface sediment, which are derived from the deeper water column, as well as the much lower amoA gene abundance and lack of amoA gene expression (Fig. 5b, d), support the contention that the crenarchaeol IPLs in the surface sediment at $885 \mathrm{~m}$ b.s.l. are predominantly fossils since evidence of active Thaumarchaeota is lacking.

The low relative abundance of GDGT-0 IPLs in the surface sediment at $885 \mathrm{~m}$ b.s.l. (Table 2) is remarkable. Only MHGDGT-0 was detected in low relative abundance $(0.3 \%)$, whereas any other of the IPL types with GDGT-0 as CL that were screened for in our study (Table S2; Fig. 1b) were absent. In contrast, Lengger et al. (2014) reported a significant amount of IPL-derived CL-GDGT-0 (i.e., $18.5 \%$ of total CL GDGTs) when the head groups of the IPLs are released by acid hydrolysis and the remaining CLs were analyzed in a surface $(0-0.5 \mathrm{~cm})$ sediment from the same site. We re-analyzed the IPL-derived CL-GDGT composition in the surface $(0-0.5 \mathrm{~cm})$ sediment at $88 \mathrm{~m}$ b.s.l. and recovered an identical CL-GDGT distribution as reported by Lengger et al. (2014). The discrepancy between CL and IPL distribution may partly be explained by the underestimation of MH IPLs by our method. To assess the MH IPL underestimation, two North Atlantic suspended particulate matter samples were analyzed with the normal phase method (this study) and the reverse phase method (Wörmer et al., 2013). This underestimation of MH IPLs with the used normal phase method could be on average 10-fold compared to the reverse phase method (Fig. S4). However, the difference in the response factor for the different IPL types is not sufficient to explain the discrepancy between IPL-derived CL-GDGT-0 and IPL GDGT0 relative abundances. Therefore, we speculate it is due to the presence of an IPL type with unknown head groups not included in our analytical window. This unknown IPL GDGT0 may originate from any of the archaeal groups present in the surface sediment at $885 \mathrm{~m}$ b.s.l., such as MCG, Thermoplasmatales, MBG-B, MBG-E and Euryarchaeota MHVG. DPANN Woesearchaeota is also relatively abundant in the surface sediments at $885 \mathrm{~m}$ b.s.l. (Fig. 1), but recent studies suggest that their small genomes lack the gene coding for the enzymes of the archaeal lipid biosynthetic pathway (Jahn et al., 2004; Podar et al., 2013; Villanueva et al., 2017; Waters et al., 2003). Therefore, they are not expected to contribute to the IPL-GDGT pool. Ruling out the Woesearchaeota as a possible source of IPL-GDGTs, the IPL GDGT-0 with unknown polar head group(s) in the surface sediment at $885 \mathrm{~m}$ b.s.l. may be attributed to the MCG, which make up $30.5 \%$ of the archaeal $16 \mathrm{~S}$ rRNA gene reads in this sediment. Most of these MCG archaea fall into subgroup MCG-15 (Table 4). Previous studies proposed butanetriol dibiphytanyl glycerol tetraethers (BDGTs) as putative biomarkers of the MCG based on the correlation between the presence of these components and MCG in estuarine sediments (Meador et al., 2015). However, we did not detect any IPL BDGTs in the sediments analyzed in our study. Buckles et al. (2013) suggested that members of the MCG and Crenarchaeota group 
1.2 could be the biological source of IPL GDGT- 0 found in the anoxic hypolimnion of a tropical lake. Considering this evidence, it is possible that the unknown IPL GDGT0 present in the surface sediment at $885 \mathrm{~m}$ b.s.l. could be a biomarker for MCG.

In subsurface sediments, the IPL GDGT distribution was remarkably different from that detected in the surface oxygenated sediment as higher relative abundances of GDGT$1,-2,-3$ and -4 were detected in detriment of GDGT-0, similar to the distribution detected in the surface sediment at $885 \mathrm{~m}$ b.s.l. This may represent new archaeal production in the anoxic sediments, selective preservation of archaeal lipids produced in the water column and surface sediments, or both. The HCP GDGT-0 and two isomers of the DH GDGT-0 (Fig. S2) were detected in the subsurface sediments at 885 and $1306 \mathrm{mb}$ b.s.l. but not in those from deeper waters (Table 2). Since these IPLs were not detected in the surface sediments, it is likely that they are produced in situ. Unfortunately, we only obtained information on the archaeal community composition of the subsurface sediments at shallow water depth, so we cannot compare these with the subsurface sediments from deeper waters that lack these DH moieties, which could have provided a clue towards the archaeal source of these IPLs. An IPL composed of GDGT-0 with a cyclopentanetetraol head group has been previously detected in cultures of the hyperthermophilic crenarchaeal Sulfolobales (Langworthy et al., 1974; Sturt et al., 2004). However, members of the Sulfolobales were not detected in our $16 \mathrm{~S}$ rRNA gene amplicon sequencing data. We also detected a high relative abundance of MCG (up to $48.4 \%$ relative abundance) in the subsurface sediment at 885 and $1306 \mathrm{mb}$ b.s.l. (Fig. 1). The diversity of the MCG population in the subsurface sediments was much higher in comparison with the diversity in surface sediments at $885 \mathrm{mb}$ b.s.l. as sequences closely related to the MCG subgroups 2, 8, 10, 14, 5b, 15, and 17 were detected both in the 885 and $1306 \mathrm{~m}$ b.s.l. subsurface sediments (Fig. 2). This presence of these different MCG members, likely caused by niche differentiation (see before), may be the origin of the unusual DH-GDGT-0 isomer and the HCP-GDGT-0 IPL that we detected within the subsurface sediments at 885 and $1306 \mathrm{~m}$ b.s.l.

\section{Conclusions}

By using a combined 16S rRNA gene amplicon sequencing and IPL analysis with high-resolution accurate mass/mass spectrometry, we have unraveled the high diversity of benthic archaea harbored in oxygenated and anoxic sediments of the Arabian Sea, as well as widening our detection window of archaeal intact polar lipids. DNA-based analyses revealed a dominance of active benthic in situ Thaumarchaeota in those sediments where oxygen was present, which coincided with high relative abundance of the HPH-crenarchaeol previously suggested to be a marker of living Thaumarchaeota. In the anoxic marine sediments analyzed here, members of the MCG, DPANN and Euryarchaeota Thermoplasmatales dominated. We also observed a high diversity within the MCG with a more diverse population in subsurface sediments. Subsurface anoxic sediments had a high relative abundance of IPL GDGT-1, -2, and -3 with DH head groups, which could be attributed either to fossil signals due to the more recalcitrant nature of the glycosidic bonds or being IPLs synthesized by the archaeal groups detected in those sediments. In addition, IPL GDGT-0 was also detected with a hexose head group on both ends of the core lipid, two hexoses on one end, and a cyclopentanetetraol molecule bound to the core lipid and a hexose attached to it. Members of the DPANN could possibly be ruled out of making those lipids due to the lack of lipid biosynthetic pathway. Dominant archaeal members in those sediments such as the MCG and Thermoplasmatales could be potential biological sources of these IPLs. To conclude, this combined approach has shed light on the possible biological sources of specific archaeal IPLs and also detected a highly diverse benthic archaeal community.

Data availability. Data are archived and available at https://doi. pangaea.de/10.1594/PANGAEA.891253 (Besseling et al., 2018).

Supplement. The supplement related to this article is available online at: https://doi.org/10.5194/bg-15-4047-2018-supplement.

Author contributions. MAB and $\mathrm{ECH}$ performed the experiments, MAB, ECH, JSSD, and LV evaluated data, RCB provided additional data, MAB, ECH, JSSD, and LV designed the experiments, and MAB, ECH, JSSD, and LV wrote the manuscript.

Competing interests. The authors declare that they have no conflict of interest.

Acknowledgements. Elda Panoto is thanked for assistance with molecular analyses. We would like to thank the captain and crew of the RV Pelagia as well as the cruise leader, technicians and scientists participating in cruise 64PE301. This PASOM cruise was funded by the Earth and Life Science and Research Council (ALW) with financial aid from the Netherlands Organization for Scientific Research (NWO) (grant 817.01.015) to Gert-Jan Reichart (PI). NIOZ is acknowledged for the studentship of Marc A. Besseling. This research was further supported by the NESSC and SIAM Gravitation Grants (024.002.001 and 024.002.002) from the Dutch Ministry of Education, Culture and Science (OCW) and the European Research Council (ERC) under the European Union's Horizon 2020 research and innovation program (grant agreement no. 694569 - MICROLIPIDS) to Jaap S. Sinninghe Damsté. We thank Julius S. Lipp, an anonymous reviewer and the associate 
editor Markus Kienast for providing constructive comments on this paper.

Edited by: Markus Kienast

Reviewed by: Julius S. Lipp and one anonymous referee

\section{References}

Altschul, S. F., Gish, W., Miller, W., Myers, E. W., and Lipman, D. J.: Basic local alignment search tool, J. Mol. Biol., 215, 403-410, https://doi.org/10.1016/S0022-2836(05)80360-2, 1990.

Besseling, M., Hopmans, E. C., Sinninghe Damsté, J. S., and Villanueva, L.: Intact polar lipid composition and bottom water and surface sediment characteristics during R/V Pelagia cruise PASOM to the Arabian Sea in 2009, PANGAEA, https://doi.org/10.1594/PANGAEA.891253, 2018.

Biddle, J. F., Lipp, J. S., Lever, M. A., Lloyd, K. G., Sørensen, K. B., Anderson, R., Fredricks, H. F., Elvert, M., Kelly, T. J., Schrag, D. P., Sogin, M. L., Brenchley, J. E., Teske, A., House, C. H., and Hinrichs, K.-U.: Heterotrophic Archaea dominate sedimentary subsurface ecosystems off Peru., P. Natl. Acad. Sci. USA, 103, 3846-3851, https://doi.org/10.1073/pnas.0600035103, 2006.

Bligh, E. G. and Dyer, W. J.: A rapid method of total lipid extraction and Purification, Can. J. Biochem. Phys., 37, 911-917, https://doi.org/10.1139/o59-099, 1959.

Boere, A. C., Rijpstra, W. I. C., de Lange, G. J., Sinninghe Damsté, J. S., and Coolen, M. J. L.: Preservation potential of ancient plankton DNA in Pleistocene marine sediments, Geobiology, 9, 377-393, https://doi.org/10.1111/j.1472-4669.2011.00290.x, 2011.

Buckles, L. K., Villanueva, L., Weijers, J. W. H., Verschuren, D., and Sinninghe Damsté, J. S.: Linking isoprenoidal GDGT membrane lipid distributions with gene abundances of ammoniaoxidizing Thaumarchaeota and uncultured crenarchaeotal groups in the water column of a tropical lake (Lake Challa, East Africa), Environ. Microbiol., 2, 1-18, https://doi.org/10.1111/14622920.12118, 2013.

Caporaso, J. G., Kuczynski, J., Stombaugh, J., Bittinger, K., Bushman, F. D., Costello, E. K., Fierer, N., Peña, A. G., Goodrich, J. K., Gordon, J. I., Huttley, G. A., Kelley, S. T., Knights, D., Koenig, J. E., Ley, R. E., Lozupone, C. A., Mcdonald, D., Muegge, B. D., Pirrung, M., Reeder, J., Sevinsky, J. R., Turnbaugh, P. J., Walters, W. A., Widmann, J., Yatsunenko, T., Zaneveld, J., and Knight, R.: correspondEnce QIIME allows analysis of high- throughput community sequencing data Intensity normalization improves color calling in SOLiD sequencing, Nat. Publ. Gr., 7, 335-336, https://doi.org/10.1038/nmeth.f.303, 2010.

Castelle, C. J., Wrighton, K. C., Thomas, B. C., Hug, L. A., Brown, C. T., Wilkins, M. J., Frischkorn, K. R., Tringe, S. G., Singh, A., Markillie, L. M., Taylor, R. C., Williams, K. H., and Banfield, J. F.: Genomic Expansion of Domain Archaea Highlights Roles for Organisms from New Phyla in Anaerobic Carbon Cycling, Curr. Biol., 25, 1-12, https://doi.org/10.1016/j.cub.2015.01.014, 2015.

Coolen, M. J. L., Muyzer, G., Rijpstra, W. I. C., Schouten, S., Volkman, J. K., and Sinninghe Damsté, J. S.: Combined DNA and lipid analyses of sediments reveal changes in Holocene haptophyte and diatom populations in an
Antarctic lake, Earth Planet. Sc. Lett., 223, 225-239, https://doi.org/10.1016/j.eps1.2004.04.014, 2004a.

Coolen, M. J. L., Hopmans, E. C., Rijpstra, W. I. C., Muyzer, G., Schouten, S., Volkman, J. K., and Sinninghe Damsté, J. S.: Evolution of the methane cycle in Ace Lake (Antarctica) during the Holocene: response of methanogens and methanotrophs to environmental change, Org. Geochem., 35, 11511167, https://doi.org/10.1016/j.orggeochem.2004.06.009, 2004b.

Cowie, G. L., Calvert, S. E., Pedersen, T. F., Schulz, H., and Von Rad, U.: Organic content and preservational controls in surficial shelf and slope sediments from the Arabian Sea (Pakistan margin), Mar. Geol., 161, 23-38, https://doi.org/10.1016/S00253227(99)00053-5, 1999.

De La Torre, J. R., Walker, C. B., Ingalls, A. E., Könneke, M., and Stahl, D. A.: Cultivation of a thermophilic ammonia oxidizing archaeon synthesizing crenarchaeol, Environ. Microbiol., 10, 810 818, https://doi.org/10.1111/j.1462-2920.2007.01506.x, 2008.

Delong, E. F. and Pace, N. R.: Environmental Diversity of Bacteria and Archaea, Soc. Syst. Biol., 50, 470-478, https://doi.org/10.1080/10635150118513, 2001.

DeLong, E. F., Ying Wu, K., Prézelin, B. B., and Jovine, R. V. M.: High abundance of Archaea in Antarctic marine picoplankton, Nature, 371, 695-697, https://doi.org/10.1038/371695a0, 1994.

De Rosa, M. and Gambacorta, A.: The lipids of archaebacteria, Prog. Lipid Res., 27, 153-175, https://doi.org/10.1016/01637827(88)90011-2, 1988.

Durbin, A. M. and Teske, A.: Sediment-associated microdiversity within the Marine Group I Crenarchaeota, Env. Microbiol. Rep., 2, 693-703, https://doi.org/10.1111/j.1758-2229.2010.00163.x, 2010.

Edgar, R. C.: MUSCLE: Multiple sequence alignment with high accuracy and high throughput, Nucleic Acids Res., 32, 1792 1797, https://doi.org/10.1093/nar/gkh340, 2004.

Elling, F. J., Konneke, M., Lipp, J. S., Becker, K. W., Gagen, E. J., and Hinrichs, K. U.: Effects of growth phase on the membrane lipid composition of the thaumarchaeon Nitrosopumilus maritimus and their implications for archaeal lipid distributions in the marine environment, Geochim. Cosmochim. Ac., 141, 579597, https://doi.org/10.1016/j.gca.2014.07.005, 2014.

Elling, F. J., Könneke, M., Mußmann, M., Greve, A., and Hinrichs, K.-U.: Influence of temperature, $\mathrm{pH}$, and salinity on membrane lipid composition and TEX86 of marine planktonic thaumarchaeal isolates, Geochim. Cosmochim. Ac., 171, 238-255, https://doi.org/10.1016/j.gca.2015.09.004, 2015.

Elling, F. J., Könneke, M., Nicol, G. W., Stieglmeier, M., Bayer, B., Spieck, E., de la Torre, J. R., Becker, K. W., Thomm, M., Prosser, J. I., Herndl, G. J., Schleper, C., and Hinrichs, K. U.: Chemotaxonomic characterisation of the thaumarchaeal lipidome, Environ. Microbiol., 19, 2681-2700, https://doi.org/10.1111/1462$2920.13759,2017$.

Fillol, M., Auguet, J.-C., Casamayor, E. O., and Borrego, C. M.: Insights in the ecology and evolutionary history of the Miscellaneous Crenarchaeotic Group lineage, ISME J., 1-13, https://doi.org/10.1038/ismej.2015.143, 2015.

Francis, C. A., Roberts, K. J., Beman, J. M., Santoro, A. E., and Oakley, B. B.: Ubiquity and diversity of ammoniaoxidizing archaea in water columns and sediments of the ocean, P. Natl. Acad. Sci. USA, 102, 14683-14688, https://doi.org/10.1073/pnas.0506625102, 2005. 
Harvey, H. R., Fallon, R. D., and Patton, J. S.: The effect of organic matter and oxygen on the degradation of bacterial membrane lipids in marine sediments, Geochim. Cosmochim. Ac., 50, 795-804, https://doi.org/10.1016/0016-7037(86)90355-8, 1986.

Hopmans, E. C., Schouten, S., and Sinninghe, J. S.: The effect of improved chromatography on GDGTbased palaeoproxies, Org. Geochem., 93, 1-6, https://doi.org/10.1016/j.orggeochem.2015.12.006, 2016.

Inagaki, F., Suzuki, M., Takai, K., Oida, H., Sakamoto, T., Aoki, K., Nealson, K. H., and Horikoshi, K.: Microbial Communities Associated with Geological Horizons in Coastal Subseafloor Sediments from the Sea of Okhotsk Microbial Communities Associated with Geological Horizons in Coastal Subseafloor Sediments from the Sea of Okhotsk, Appl. Environ. Microbiol., 69, 7224-7235, https://doi.org/10.1128/AEM.69.12.72247235.2003, 2003.

Ingalls, A. E., Huguet, C., and Truxal, L. T.: Distribution of intact and core membrane lipids of archaeal glycerol dialkyl glycerol tetraethers among size-fractionated particulate organic matter in Hood Canal, Puget Sound, Appl. Environ. Microbiol., 78, 1480 1490, https://doi.org/10.1128/AEM.07016-11, 2012.

Jahn, U., Summons, R., Sturt, H., Grosjean, E., and Huber, H.: Composition of the lipids of Nanoarchaeum equitans and their origin from its host Ignicoccus sp. strain KIN4/I, Arch. Microbiol., 182, 404-413, https://doi.org/10.1007/s00203-004-0725-x, 2004.

Jorgenson, S. L., Hannisdal, B., Lanzén, A., Baumberger, T., Flesland, K., Fonseca, R., Øvreås, L., Steen, I. H., Thorseth, I. H., Pedersen, R. B., and Schleper, C.: Correlating microbial community pro fi les with geochemical data in highly strati fi ed sediments from the Arctic MidOcean Ridge, P. Natl. Acad. Sci. USA, 109, E2846-E2855, https://doi.org/10.1594/PANGAEA.786687, 2012.

Karner, M. B., DeLong, E. F., and Karl, D. M.: Archaeal dominance in the mesopelagiczone of the Pacific Ocean, Nature, 409, 507510, https://doi.org/10.1038/35054051, 2001.

Klindworth, A., Pruesse, E., Schweer, T., Peplies, J., Quast, C., Horn, M., and Glockner, F. O.: Evaluation of general 16S ribosomal RNA gene PCR primers for classical and next-generation sequencing-based diversity studies, Nucleic Acids Res., 41, 111, https://doi.org/10.1093/nar/gks808, 2013.

Koga, Y. and Morii, H.: Biosynthesis of ether-type polar lipids in archaea and evolutionary considerations, Microbiol. Mol. Biol. R., 71, 97-120, https://doi.org/10.1128/MMBR.00033-06, 2007.

Koho, K. A., Nierop, K. G. J., Moodley, L., Middelburg, J. J., Pozzato, L., Soetaert, K., van der Plicht, J., and Reichart, G.J.: Microbial bioavailability regulates organic matter preservation in marine sediments, Biogeosciences, 10, 1131-1141, https://doi.org/10.5194/bg-10-1131-2013, 2013.

Könneke, M., Bernhard, A. E., de la Torre, J. R., Walker, C. B., Waterbury, J. B., and Stahl, D. A.: Isolation of an autotrophic ammonia-oxidizing marine archaeon, Nature, 437, 543-546, https://doi.org/10.1038/nature03911, 2005.

Kraal, P., Slomp, C. P., Reed, D. C., Reichart, G.-J., and Poulton, S. W.: Sedimentary phosphorus and iron cycling in and below the oxygen minimum zone of the northern Arabian Sea, Biogeosciences, 9, 2603-2624, https://doi.org/10.5194/bg-9-26032012, 2012.
Kubo, K., Lloyd, K. G., Biddle, J. F., Amann, R., Teske, A., and Knittel, K.: Archaea of the Miscellaneous Crenarchaeotal Group are abundant, diverse and widespread in marine sediments, ISME J., 6, 1949-1965, https://doi.org/10.1038/ismej.2012.37, 2012.

Langworthy, T. A., Mayberry, W. R., and Smith, P. F.: Long-chain glycerol diether and polyol dialkyl glycerol triether lipids of Sulfolobus acidocaldarius, J. Bacteriol., 119, 106-116, 1974.

Lazar, C. S., Baker, B. J., Seitz, K., Hyde, A. S., Dick, G. J., Hinrichs, K. U., and Teske, A. P.: Genomic evidence for distinct carbon substrate preferences and ecological niches of Bathyarchaeota in estuarine sediments, Environ. Microbiol., 18, 1200-1211, https://doi.org/10.1111/1462-2920.13142, 2016.

Learman, D. R., Henson, M. W., Thrash, J. C., Temperton, B., Brannock, P. M., Santos, S. R., Mahon, A. R., and Halanych, K. M.: Biogeochemical and microbial variation across $5500 \mathrm{~km}$ of Antarctic surface sediment implicates organic matter as a driver of benthic community structure, Front. Microbiol., 7, 111, https://doi.org/10.3389/fmicb.2016.00284, 2016.

Lengger, S. K., Hopmans, E. C., Reichart, G.-J., Nierop, K. G. J., Sinninghe Damsté, J. S., and Schouten, S.: Intact polar and core glycerol dibiphytanyl glycerol tetraether lipids in the Arabian Sea oxygen minimum zone. Part II: Selective preservation and degradation in sediments and consequences for the TEX86, Geochim. Cosmochim. Ac., 98, 244258, https://doi.org/10.1016/j.gca.2012.05.003, 2012.

Lengger, S. K., Hopmans, E. C., Sinninghe Damsté, J. S., and Schouten, S.: Impact of sedimentary degradation and deep water column production on GDGT abundance and distribution in surface sediments in the Arabian Sea: Implications for the TEX86 paleothermometer, Geochim. Cosmochim. Ac., 142, 386-399, https://doi.org/10.1016/j.gca.2014.07.013, 2014.

Lincoln, S. A., Wai, B., Eppley, J. M., Church, M. J., Summons, R. E., and DeLong, E. F.: Planktonic Euryarchaeota are a significant source of archaeal tetraether lipids in the ocean, P. Natl. Acad. Sci. USA, 111, 9858-9863, https://doi.org/10.1073/pnas.1409439111, 2014a.

Lincoln, S. A., Wai, B., Eppley, J. M., Curch, M. J., Summons, R. E., and Delong, E. F.: Reply to Schouten et al.: Marine Group II planktonic Euryarchaeota are significant contributors to tetraether lipids in the ocean, P. Natl. Acad. Sci. USA, 111, 4286, https://doi.org/10.1073/pnas.1416736111, 2014b.

Lipp, J. S. and Hinrichs, K.-U.: Structural diversity and fate of intact polar lipids in marine sediments, Geochim. Cosmochim. Ac., 73, 6816-6833, https://doi.org/10.1016/j.gca.2009.08.003, 2009.

Lipp, J. S., Morono, Y., Inagaki, F., and Hinrichs, K.U.: Significant contribution of Archaea to extant biomass in marine subsurface sediments, Nature, 454, 991-994, https://doi.org/10.1038/nature07174, 2008.

Lloyd, K. G., Schreiber, L., Petersen, D. G., Kjeldsen, K. U., Lever, M. A., Steen, A. D., Stepanauskas, R., Richter, M., Kleindienst, S., Lenk, S., Schramm, A., and Jørgensen, B. B.: Predominant archaea in marine sediments degrade detrital proteins, Nature, 496, 215-218, https://doi.org/10.1038/nature12033, 2013.

Ludwig, W., Strunk, O., Westram, R., Richter, L., Meier, H., Yadhukumar, Buchner, A., Lai, T., Steppi, S., Jobb, G., Förster, W., Brettske, I., Gerber, S., Ginhart, A. W., Gross, O., Grumann, S., Hermann, S., Jost, R., König, A., Liss, T., Lüssmann, R., May, M., Nonhoff, B., Reichel, B., Strehlow, R., Stamatakis, A., Stuckmann, N., Vilbig, A., Lenke, M., Ludwig, 
T., Bode, A., and Schleifer, K.-H.: ARB: a software environment for sequence data, Nucleic Acids Res., 32, 1363-1371, https://doi.org/10.1093/nar/gkh293, 2004.

Massana, R., Castresana, J., Balague, V., Guillou, L., Romari, K., Groisillier, A., Valentin, K., and Pedros-Alio, C.: Phylogenetic and Ecological Analysis of Novel Marine Stramenopiles, Appl. Environ. Microbiol., 70, 3528-3534, https://doi.org/10.1128/AEM.70.6.3528-3534.2004, 2004.

Meador, T. B., Bowles, M., Lazar, C. S., Zhu, C., Teske, A., and Hinrichs, K.-U.: The archaeal lipidome in estuarine sediment dominated by members of the Miscellaneous Crenarchaeotal Group, Environ. Microbiol., 17, 2441-2458, https://doi.org/10.1111/1462-2920.12716, 2015.

Meng, J., Xu, J., Qin, D., He, Y., Xiao, X., and Wang, F.: Genetic and functional properties of uncultivated MCG archaea assessed by metagenome and gene expression analyses, ISME J., 8, 650659, https://doi.org/10.1038/ismej.2013.174, 2014.

Moore, E. K., Villanueva, L., Hopmans, E. C., Rijpstra, W. I. C., Mets, A., Dedysh, S. N., and Sinninghe Damsté, J. S.: Abundant trimethylornithine lipids and specific gene sequences are indicative of planctomycete importance at the oxic/anoxic interface in sphagnum-dominated northern wetlands, Appl. Environ. Microbiol., 81, 6333-6344, https://doi.org/10.1128/AEM.00324$15,2015$.

Nierop, K. G. J., Reichart, G., Veld, H., and Sinninghe Damsté, J. S.: The influence of oxygen exposure time on the composition of macromolecular organic matter as revealed by surface sediments on the Murray Ridge (Arabian Sea), Geochim. Cosmochim. Ac., 206, 40-56, 2017.

Offre, P., Spang, A., and Schleper, C.: Archaea in Biogeochemical Cycles, Annu. Rev. Microbiol., 437-457, https://doi.org/10.1146/annurev-micro-092412-155614, 2013.

Oni, O. E., Schmidt, F., Miyatake, T., Kasten, S., Witt, M., Hinrichs, K.-U., and Friedrich, M. W.: Microbial Communities and Organic Matter Composition in Surface and Subsurface Sediments of the Helgoland Mud Area, North Sea, Front. Microbiol., 6, 116, https://doi.org/10.3389/fmicb.2015.01290, 2015.

Park, S.-J., Park, B.-J., and Rhee, S.-K.: Comparative analysis of archaeal 16S rRNA and amoA genes to estimate the abundance and diversity of ammonia-oxidizing archaea in marine sediments, Extremophiles, 12, 605-615, https://doi.org/10.1007/s00792-0080165-7, 2008.

Pitcher, A., Rychlik, N., Hopmans, E. C., Spieck, E., Rijpstra, W. I. C., Ossebaar, J., Schouten, S., Wagner, M., and Sinninghe Damsté, J. S.: Crenarchaeol dominates the membrane lipids of Candidatus Nitrososphaera gargensis, a thermophilic group I.1b Archaeon, ISME J., 4, 542-552, https://doi.org/10.1038/ismej.2009.138, 2010.

Pitcher, A., Villanueva, L., Hopmans, E. C., Schouten, S., Reichart, G.-J., and Sinninghe Damsté, J. S.: Niche segregation of ammonia-oxidizing archaea and anammox bacteria in the Arabian Sea oxygen minimum zone, ISME J., 5, 1896-904, https://doi.org/10.1038/ismej.2011.60, 2011.

Podar, M., Makarova, K. S., Graham, D. E., Wolf, Y. I., Koonin, E. V., and Reysenbach, A.-L.: Insights into archaeal evolution and symbiosis from the genomes of a nanoarchaeon and its inferred crenarchaeal host from Obsidian Pool, Yellowstone National Park, Biol. Direct, 8, 1-20, https://doi.org/10.1186/17456150-8-9, 2013.
Quast, C., Pruesse, E., Yilmaz, P., Gerken, J., Schweer, T., Yarza, P., Peplies, J., and Glockner, F. O.: The SILVA ribosomal RNA gene database project: improved data processing and web-based tools, Nucleic Acids Res., 41, D590-D596, https://doi.org/10.1093/nar/gks1219, 2013.

Rinke, C., Schwientek, P., Sczyrba, A., Ivanova, N. N., Anderson, I. J., Cheng, J.-F., Darling, A. E., Malfatti, S., Swan, B. K., Gies, E. A., Dodsworth, J. A., Hedlund, B. P., Tsiamis, G., Sievert, S. M., Liu, W.-T., Eisen, J. A., Hallam, S. J., Kyrpides, N. C., Stepanauskas, R., Rubin, E. M., Hugenholtz, P., and Woyke, T.: Insights into the phylogeny and coding potential of microbial dark matter, Nature, 499, 431-437, https://doi.org/10.1038/nature12352, 2013.

Rossel, P. E., Lipp, J. S., Fredricks, H. F., Arnds, J., Boetius, A., Elvert, M., and Hinrichs, K. U.: Intact polar lipids of anaerobic methanotrophic archaea and associated bacteria, Org. Geochem., 39, 992-999, https://doi.org/10.1016/j.orggeochem.2008.02.021, 2008.

Saitou, N. and Nei, M.: The Neighbor-joining Method: A New Method for Reconstructing Phylogenetic Trees, Mol. Biol. Evol., 4, 406-425, 1987.

Schleper, C., Jurgens, G., and Jonuscheit, M.: Genomic studies of uncultivated archaea, Nat. Rev. Microbiol., 3, 479-488, https://doi.org/10.1038/nrmicro1159, 2005.

Schouten, S., Hopmans, E. C., Baas, M., Boumann, H., Standfest, S., Könneke, M., Stahl, D. A., and Sinninghe Damsté, J. S.: Intact membrane lipids of "Candidatus Nitrosopumilus maritimus," a cultivated representative of the cosmopolitan mesophilic group I crenarchaeota, Appl. Environ. Microbiol., 74, 2433-2440, https://doi.org/10.1128/AEM.01709-07, 2008.

Schouten, S., Middelburg, J. J., Hopmans, E. C., and Sinninghe Damsté, J. S.: Fossilization and degradation of intact polar lipids in deep subsurface sediments: A theoretical approach, Geochim. Cosmochim. Ac., 74, 3806-3814, https://doi.org/10.1016/j.gca.2010.03.029, 2010.

Schouten, S., Pitcher, A., Hopmans, E. C., Villanueva, L., van Bleijswijk, J., and Sinninghe Damsté, J. S.: Intact polar and core glycerol dibiphytanyl glycerol tetraether lipids in the Arabian Sea oxygen minimum zone: I. Selective preservation and degradation in the water column and consequences for the TEX86, Geochim. Cosmochim. Ac., 98, 228-243, https://doi.org/10.1016/j.gca.2012.05.002, 2012.

Schouten, S., Hopmans, E. C., and Sinninghe Damsté, J. S.: The organic geochemistry of glycerol dialkyl glycerol tetraether lipids: A review, Org. Geochem., 54, 19-61, https://doi.org/10.1016/j.orggeochem.2012.09.006, 2013.

Schouten, S., Villanueva, L., Hopmans, E. C., van der Meer, M. T. J., and Sinninghe Damsté, J. S.: Are Marine Group II Euryarchaeota significant contributors to tetraether lipids in the ocean?, P. Natl. Acad. Sci. USA, 111, E4285, https://doi.org/10.1073/pnas.1416176111, 2014.

Schubotz, F., Wakeham, S. G., Lipp, J. S., Fredricks, H. F., and Hinrichs, K.-U.: Detection of microbial biomass by intact polar membrane lipid analysis in the water column and surface sediments of the Black Sea, Environ. Microbiol., 11, 2720-2734, https://doi.org/10.1111/j.1462-2920.2009.01999.x, 2009.

Sinninghe Damsté, J. S., Schouten, S., Hopmans, E. C., van Duin, A. C. T., and Geenevasen, J. A. J.: Crenarchaeol: the characteristic core glycerol dibiphytanyl glycerol tetraether membrane lipid 
of cosmopolitan pelagic crenarchaeota, J. Lipid Res., 43, 16411651, https://doi.org/10.1194/jlr.M200148-JLR200, 2002.

Sinninghe Damsté, J. S., Rijpstra, W. I. C., Hopmans, E. C., Jung, M.-Y., Kim, J.-G., Rhee, S.-K., Stieglmeier, M., and Schleper, C.: Intact Polar and Core Glycerol Dibiphytanyl Glycerol Tetraether Lipids of Group I.1a and I.1b Thaumarchaeota in Soil, Appl. Environ. Microbiol., 78, 6866-6874, https://doi.org/10.1128/AEM.01681-12, 2012.

Spang, A., Caceres, E. F., and Ettema, T. J. G.: Genomic exploration of the diversity, ecology, and evolution of the archaeal domain of life, Science, 357, 1-10, https://doi.org/10.1126/science.aaf3883, 2017.

Stetter, K. O., Fiala, G., Huber, G., Huber, R., and Segerer, A.: Hyperthermophilic microorganisms, FEMS Microbiol. Rev., 75, 117-124, https://doi.org/10.1111/j.1574-6968.1990.tb04089.x, 1990.

Sturt, H. F., Summons, R. E., Smith, K., Elvert, M., and Hinrichs, K.-U.: Intact polar membrane lipids in prokaryotes and sediments deciphered by high-performance liquid chromatography/electrospray ionization multistage mass spectrometry - new biomarkers for biogeochemistry and microbial ecology, Rapid Commun. Mass Spectrom., 18, 617-628, https://doi.org/10.1002/rcm.1378, 2004.

Sugai, A., Sakuma, R., Fukuda, I., Kurosawa, N., and Itoh, Y. H.: The Structure of the Core Polyol of the Ether Lipids from Sulfolobus acidocaldarius, Lipids, 30, 339-344, https://doi.org/10.1007/BF02536042, 1995.

Teske, A.: Marine deep sediment microbial communities, in: The Prokaryotes, edited by: Rosenberg, E., DeLong, E. F., Lory, S., Stackebrandt, E., and Thompson, F., Springer, Berlin, Heidelberg, 2013.

Teske, A. and Sørensen, K. B.: Uncultured archaea in deep marine subsurface sediments: have we caught them all?, ISME J., 2, 318, https://doi.org/10.1038/ismej.2007.90, 2008.
Villanueva, L., Schouten, S., and Sinninghe Damsté, J. S.: Depthrelated distribution of a key gene of the tetraether lipid biosynthetic pathway in marine Thaumarchaeota, Environ. Microbiol., 17, 3527-3539, https://doi.org/10.1111/1462-2920.12508, 2014.

Villanueva, L., Schouten, S., and Sinninghe Damsté, J. S.: Phylogenomic analysis of lipid biosynthetic genes of Archaea shed light on the "lipid divide", Environ. Microbiol., 19, 54-69, https://doi.org/10.1111/1462-2920.13361, 2017.

Waters, E., Hohn, M. J., Ahel, I., Graham, D. E., Adams, M. D., Barnstead, M., Beeson, K. Y., Bibbs, L., Bolanos, R., Keller, M., Kretz, K., Lin, X., Mathur, E., Ni, J., Podar, M., Richardson, T., Sutton, G. G., Simon, M., Soll, D., Stetter, K. O., Short, J. M., and Noordewier, M.: The genome of Nanoarchaeum equitans: insights into early archaeal evolution and derived parasitism, P. Natl. Acad. Sci. USA, 100, 12984-12988, https://doi.org/10.1073/pnas.1735403100, 2003.

Wörmer, L., Lipp, J. S., Schröder, J. M., and Hinrichs, K. U.: Application of two new LC-ESI-MS methods for improved detection of intact polar lipids (IPLs) in environmental samples, Org. Geochem., 59, 10-21, https://doi.org/10.1016/j.orggeochem.2013.03.004, 2013.

Xie, S., Lipp, J. S., Wegener, G., Ferdelman, T. G., and Hinrichs, K.U.: Turnover of microbial lipids in the deep biosphere and growth of benthic archaeal populations, P. Natl. Acad. Sci. USA, 110, 6010-6014, https://doi.org/10.1073/pnas.1218569110, 2013.

Yakimov, M. M., Cono, V. La, Smedile, F., DeLuca, T. H., Juárez, S., Ciordia, S., Fernández, M., Albar, J. P., Ferrer, M., Golyshin, P. N., and Giuliano, L.: Contribution of crenarchaeal autotrophic ammonia oxidizers to the dark primary production in Tyrrhenian deep waters (Central Mediterranean Sea), ISME J., 5, 945-961, https://doi.org/10.1038/ismej.2010.197, 2011.

Yu, T., Wu, W., Liang, W., Lever, M. A., Hinrichs, K., and Wang, F.: Growth of sedimentary Bathyarchaeota on lignin as an energy source, P. Natl. Acad. Sci. USA, 1-6, https://doi.org/10.1073/pnas.1718854115, 2018. 